\title{
Moldova / Moldavie. Historique
}

\section{Marina Chiriac}

\section{(2) OpenEdition}

\section{Journals}

Édition électronique

URL : https://journals.openedition.org/cher/10386

DOI : $10.4000 /$ cher.10386

ISSN : 2803-5992

\section{Éditeur}

Presses universitaires de Strasbourg

\section{Édition imprimée}

Date de publication : 1 décembre 2013

Pagination : 135-201

ISBN : 978-2-86820-560-5

ISSN : 1968-035X

\section{Référence électronique}

Marina Chiriac, « Moldova / Moldavie. Historique », reCHERches [En ligne], 11 | 2013, mis en ligne le 08 février 2022, consulté le 09 février 2022. URL : http://journals.openedition.org/cher/10386 ; DOI : https://doi.org/10.4000/cher.10386

\section{cc) (i) (-)}

Ce(tte) œuvre est mise à disposition selon les termes de la Licence Creative Commons Attribution Pas d'Utilisation Commerciale - Partage dans les Mêmes Conditions 4.0 International. 


\title{
Moldova / Moldavie. Historique
}

\author{
Marina ChIRIAC \\ Université de Strasbourg
}

\begin{abstract}
T a République de Moldova, territoire occupant le tiers central de Ll'ancienne Bessarabie (Nouzille, 2004: 6) est un petit État aux limites géographiques mal définissables d'un mot en raison des fluctuations historiques liées à la mobilité des frontières, au morcellement du territoire et en raison du fait qu'elle a connu au long des siècles diverses appellations sous l'influence des grands empires qui convoitaient sa position stratégique (Larousse:1). Cette région dont les première traces d'occupation attribuées au IV siècle av. J.-C. aux Daces, ascendants du peuple moldave (Vilaldach, 1999:2) a subi l'invasion des peuples migratoires (Ruzé, 1997: 10) puis a été l'objet de la convoitise des voisins hongrois, polonais, turcs, autrichiens, russes. Durant plusieurs siècles, des mouvements alternatifs constants ont eu lieu sur l'actuel territoire: indépendant au début, il sera successivement goubernia (province) russe, région roumaine, puis république socialiste soviétique avant d'acquérir son indépendance.
\end{abstract}

Le territoire actuel du pays a connu différentes appellations. La première: Principauté de Moldavie (1359-1812) est une dénomination historique et géographique 3 . La seconde: Bessarabie (1812-1944) désigne l'appartenance

1 http://www.larousse.fr/encyclopedie/pays/Moldavie/133596

2 http://www.regard-est.com/home/breve_contenu.php?id=592

3 Son utilisation est justifiée par le fait qu'à l'intérieur de l'URSS, ce territoire était connu sous ce nom (par comparaison avec la période tsariste qui l'appelait Bessarabie).

4 Entre 1812 et 1918, le territoire de la Bessarabie a été incorporé à l'Empire russe, rattaché à la Roumanie de 1918 à 1940 . Cette région qui a été annexée par l'URSS entre 1940 et 1941 a fait partie de la Roumanie de 1941 à 1944. 
ethnique, culturelle, historique à l'espace roumain. La troisième: République socialiste soviétique de Moldavie (1945-1991) $)^{5}$ qualifie l'une des quinze républiques de l'URSS. Enfin, la dernière: République de Moldova (1991) désigne un pays désormais indépendant. L'usage de ces noms vise à «réconcilier» une réalité récente avec une réalité historique plus ancienne de plusieurs siècles (Caşu, 2000:7). Et puisqu'il faut remonter loin et fournir autant de précisions que possible pour énoncer en termes compréhensibles l'objet de ce texte, soulignons que nous avons affaire à une histoire compliquée, passionnante et mal connue.

\section{Des origines à la création de la Principauté}

Le territoire situé entre "[...] le Danube et la mer Noire au Sud, les rivières: Mureș, Siret, Prutau Nord, les Carpates à l'Ouest, les plaines de Bessarabie [...]» (Serbesco, 1918: 51) et le Dniestr à l'Est, a été nommé Dacie ${ }^{6}$. Ses occupants, les Daces ${ }^{7}$ faisaient partie de la grande famille des Thraces $^{8}$ et ils étaient unis politiquement (Bergmann, 1859: 42). Suite à sa conquête en 107 après J.-C. par les légions de l'Empereur romain Trajan, la Dacie a été transformée en province romaine (Kogălniceanu, 1837: 9) nommée Dacie Romaine. Nicolae Iorga écrivait dans son ouvrage Histoire des Roumains et de leur civilisation: "[...] Trajan colonisa la Dacie puis fit venir des colons latinisés [...]» (Iorga, 1920:28) de différentes parties de l'Empire (Italie, Grèce, Croatie, Slovénie, Albanie, Espagne, Asie Mineure, Gaule). Au premier fond ethnique des Roumains: le dace, s'est ajouté un second facteur lié à la civilisation latine (Goga, 2006: 14). Comme nous le montre justement un membre de l'Académie Roumaine,

«dans la zone sud-est européenne du continent s'était constituée "une puissante et large communauté de civilisation et de langue romaine» et «à l'intérieur de laquelle se trouvaient, les Daco-Romains, résultat de la fusion des Daces avec les Romains» (Berindei, 2003: ${ }^{9}$.

5 Territoire correspondant à la République de Moldova d'aujourd'hui.

6 Le royaume de Dacie est attesté dès le II siècle avant notre ère.

7 Dès le viI ${ }^{\mathrm{e}}$ siècle av. J.-C., les Grecs établirent des colonies commerciales tout au long des côtes de la mer Noire, ce qui favorisa les contacts avec ces peuples que les Grecs appelèrent Gètes et les Romains, plus tard, Daces.

8 Les Thraces s'étendirent au cours de l'histoire sur des régions d' Allemagne, Pologne, Slovaquie, Autriche, Hongrie, Serbie, Bulgarie, nord-est de la Grèce, Turquie (partie européenne et Asie Mineure occidentale), Roumanie, Moldova, Ukraine (jusqu'au Dniepr), Volga inférieure et Tadjikistan.

9 http://www.dirittoestoria.it/memorie2/Testi\%20delle\%20Comunicazioni/BerindeiConstantin-Le-Grand.htm 
La romanisation a été favorisée par la mise en place des structures administratives et des civitates ${ }^{10}$ de même que par l'urbanisation, l'intégration à l'armée ou l'adhésion aux cultes romains. L'inclusion des Daces dans le système de la civilisation romaine par la participation à la vie urbaine et au commerce entraînait des mutations profondes dans la société. La romanisation n'a pas été uniquement une soumission économique, commerciale, politique et administrative mais plutôt une assimilation culturelle (Iancu, 2005: 7) qui a conduit à « imposer une mentalité, une façon de penser et [...] la langue du conquérant» (Weinreich, 1975: 40). Pour que le processus d'assimilation ethnoculturelle des autochtones se développe, les colons ont d'abord constitué de solides communautés de langue latine, ce qui a conduit d'abord au bilinguisme puis au remplacement de la langue des autochtones par le latin.

Le latin vulgaire (populaire) ${ }^{11}$ parlé par les Romains qui a servi d'instrument à la création de l'unité linguistique, a été repris par les Daces puis a évolué sur le fondement linguistique autochtone "devenant après nombre de mélanges ultérieurs» (Iorga, 1920: 29) quelques siècles plus tard - la langue roumaine ${ }^{12}$. L'usage de la langue roumaine aujourd'hui plaide en faveur de cette continuité, la grammaire étant entièrement latine et le vocabulaire en majorité d'origine latine. En Dacie ont été retrouvées 3000 inscriptions latines alors que 35 seulement sont grecques. De plus sur 3150 anthroponymes, environ $75 \%$ sont romains, $15 \%$ sont grecs et $4 \%$ à peine thraco-daces (Berindei, $\left.2003:{ }^{13}\right)$. La toponymie des cités, plaines et cours d'eau est restée exclusivement latine en Valachie, Bucovine, Moldavie et Bessarabie.

La romanisation conduisait progressivement à l'assimilation par la population locale de divers éléments de la civilisation romaine. La ressemblance entre les éléments traditionnels daces et roumains, comme le montre la Colonne Trajane à Rome (Marinescu-Nicolaj, 1999: 284-285),

10 Territoires occupés par des communautés de citoyens (les tributs ont fini par se désintégrer).

11 Qui seul a pu leur servir de langue véhiculaire (vecteur de promotion sociale dans l'administration romaine).

12 D'après son caractère, c'est une langue romaine orientale, faisant partie du groupe de langues néolatines qui a gardé du fond linguistique daco-gète/substrat thrace antérieur à la conquête romaine approximativement 300 mots. Une grande partie du vocabulaire roumain de base est issue directement du latin (80\%-85\%).

13 http://www.dirittoestoria.it/memorie2/Testi\%20delle\%20Comunicazioni/BerindeiConstantin-Le-Grand.htm 
constitue un argument majeur en faveur de l'hypothèse révélant que «les Daco-Romains sont les ancêtres des Roumains» (Berg, 1918: 46). C'est dans cette province latinophone que les Roumains sont nés.

Cette latinité resta ignorée jusqu'au $\mathrm{xvII}^{\mathrm{e}}$ siècle, quand le chroniqueur moldave Ureche G., auteur de Letopisețul Țării Moldovei (Chronique du Pays de Moldavie) 1640, affirma la descendance romaine «nous descendons de Rome» et constata que la langue roumaine est l'héritière d'un riche fonds latin. Il soutint cette idée en s'appuyant sur un matériel linguistique et établit des corrélations lexicales et rapprochements etymologiques entre mots roumains et latins dont voici quelques exemples: paine $\rightarrow$ panis; carne $\rightarrow$ caro ; gaina $\rightarrow$ galina; muiarea $\rightarrow$ mulier ; fameia $\rightarrow$ femina; parinte $\rightarrow$ pater ; al nostru $\rightarrow$ noster. L'auteur conclut que beaucoup d'autres mots viennent de la langue latine et «[...] si l'on cherche minutieusement (en détail), il serait possible de comprendre tous les mots» (Ureche, 1998: 11).

En 212 ap. J.-C., au même titre que tous les hommes libres de l'Empire Romain, les Daco-Romains deviennent des citoyens romains. Après le retrait de l'armée et de l'administration romaines de Dacie sur ordre de l'Empereur Aurélien (entre 271 et 275 ap. J.-C.), la Dacie continuera d'être considérée comme un "territoire du monde romain» (Iorga, 1920: 30) dont l'évacuation ne fut pas définitive ${ }^{14}$, offrant un cadre plus large au processus de romanisation. En 313 ap. J.-C., avec la reconnaissance par l'Empereur Constantin le Grand de la religion chrétienne (le catholicisme romain ${ }^{15}$ comme religion officielle de l'ensemble de l'Empire Romain, les Daco-Romains deviennent chrétiens. Constantin le Grand restaure l'unité de l'Empire Romain mais lui donne une nouvelle capitale Constantinople (en 330 ap. J.-C.), conçue comme une Nouvelle Rome. C'est de son empire qu'émerge l'État Byzantin ${ }^{16}$. Son rôle fut des plus importants, contribuant au parachèvement du processus de romanisation de l'espace dace donc au maintien de la romanité orientale.

Dès le début de leur histoire étatique, les Roumains furent au contact des traditions culturelles et politiques des pays voisins. Situés aux confins de l'Europe, dans «un pays prolifique, une région paradisiaque» (Goga, 2006: 10), ils étaient au carrefour d'influences politique, économique, religieuse, culturelle: d'abord de l'Empire romain (l'Empire romain d'Occident) jusqu'en 476 ap. J.-C., et après la scission ${ }^{17}$ sous celle de

14 L'Empereur Aurélien avait maintenu des garnisons sur ce territoire (à Drobeta et Sucidava).

15 À la croyance dans les vieilles divinités (culte de Mithra) se superposa un élément chrétien.

16 La partie orientale de l'Empire Romain, qui est la continuation de l'ancien Empire Romain.

$17 \mathrm{Au}$ cours des siècles suivants, l'Empire byzantin et Constantinople (sa capitale) maintiennent l'Empire et l'influence romaine dans la moitié orientale des possessions de 
l'Empire byzantin - Empire gréco-romain d'Orient sur le Bas-Danube jusqu'en 145318) - (Stănescu, 1971: 41), la deuxième Rome. Tandis que deux composantes de l'identité roumaine dérivent de l'Empire Romain dont les Roumains ont hérité, à savoir l'origine et la langue, une troisième dérive pour sa part, de l'Empire Byzantin duquel ils ont hérité la foi orthodoxe. La chute de Byzance permet à Moscou de se proclamer la Troisième Rome.

\section{Opposition aux influences}

Les invasions survenues lors du long processus de création de la Principauté de Moldavie ont entraîné des influences sur les aspects linguistiques, migratoires et religieux.

Le peuple roumain et la langue roumaine ont subi durant des siècles, la domination étrangère. La langue des Daco-Romains conservera sa structure romane mais en fonction des influences culturelles, elle intègrera principalement des mots slaves ${ }^{19}$, grecs, hongrois, turcs comme le remarque G. Ureche: «[...] et notre langue est formée à partir de plusieurs langues et [notre] parler est un mélange de notre langage et de celui de nos voisins alentours» (Ureche, 1998: 11).

$\mathrm{Au} \mathrm{IV}^{\mathrm{e}}$ siècle commence une période durant laquelle, en l'absence d'une autorité étatique durable, ce peuple subit de fréquentes invasions de nomades guerriers et d'importantes migrations. La population d'origine latine se mélange à des peuples germaniques: les Bastarnes (II ${ }^{\mathrm{e}}$ siècle) à des Scandinaves, les Goths (III ${ }^{\mathrm{e}}$ siècle) (Kogălniceanu 1837:12) à des nomades iraniens les Iazyges (III ${ }^{\mathrm{e}}$ siècle) puis à des nomades turco-mongols de l'Asie centrale - les Huns et les Avars (IV siècle) (Iorga, 1920: 17). À ces influences barbares, vient s'ajouter une grande influence de l'Empire Byzantin (Empire romain d'Orient ${ }^{20}$ ).

À partir de 476 ap. J.-C., l'Empire romain d'Orient s'est «déromanisé» et a pris un caractère grec «[...] remplaçant les aigles latins par les aigles byzantins $[\ldots] »\left(\right.$ Xenopol, 1896: 140) ${ }^{21}$. Ce fait a pour conséquence la rupture

Rome.

18 La date de la chute de Constantinople aux mains des Ottomans.

19 Le superstrat slave constitue $10 \%$ ou $15 \%$ des mots, influence qui a continué par les emprunts aux langues slaves voisines ou proches : bulgare, russe, serbe, ukrainien, polonais.

20 Nom donné depuis le $\mathrm{xVII}^{\mathrm{e}}$ siècle à l'Empire romain d'Orient, Etat multiethnique, comptant, outre les Grecs, des Arméniens, des Valaques, des Slaves.

21 Les Byzantins, dont la langue de communication et la culture étaient essentiellement grecs, eux se considéraient comme des Romains. Les empereurs Byzantins puisent dans 
culturelle et linguistique, la romanité orientale évoluant indépendamment sans l'appui de l'autorité romaine. L'élément roman s'est affaibli encore et a disparu en raison de " [...] l'ascendant pris avec le temps par les Grecs et plus tard les Slaves dans les affaires politiques» (Densuşianu, 1901: 52).

Le peuple a eu à souffrir de l'invasion des Slaves (dans leur expansion vers les Balkans au vi ${ }^{e}$ siècle) qui «s'établirent au milieu d'eux, introduisant l'élément slavon" (Xenopol, 1885: 2), comme le mentionne l'historien roumain, Xenopol A.D. Leur pénétration dans cette zone a mis en péril l'existence de la communauté ethnolinguistique est-romaine danubienne. La romanité a été obligée de vivre dans un milieu culturel et linguistique hostile (Iancu, 2005: 8), c'est-à-dire de défendre son identité par des efforts et des sacrifices énormes. Les Slaves ont en effet donné à ce peuple ${ }^{22}$ un modèle politique, un alphabet cyrillique adapté à leur langue et une religion qui est encore la leur aujourd'hui. Ce peuple a été soumis aux Bulgares qui fondèrent au $\mathrm{VII}^{\mathrm{e}}$ siècle le premier Empire bulgare étendu sur les actuelles Serbie, Macédoine, Bulgarie, Roumanie et République de Moldova. Les Bulgares migrèrent des steppes du nord du Caucase et de la mer Azov vers les Balkans, partis de la steppe russe pour arriver au delta du Danube (Iorga, 1920: 11). Ainsi, ils ont fini par être assimilés aux Slaves et se sont convertis au Christianisme. La "moitié de la population est latinophone $»^{23}$, phénomène qui amena une «[...] fusion plus intime de l'élément latin et de l'élément slave [...]»(Caterly, 1908: 30). De plus, l'Église orthodoxe bulgare fondée au IX ${ }^{\mathrm{e}}$ siècle par des missionnaires venus de Byzance fit du slavon (vieux-slave) écrit en alphabet cyrillique une langue liturgique, tout en essayant avec un succès très relatif de l'implanter dans le peuple dacoRomain ${ }^{24}$ comme langue maternelle, la population continuant de parler le daco-romain. Ainsi le slavisme qui mena le vocabulaire propre à exprimer son «nouvel état de dépendance» (Călinescu, 1997: 19) était sur le point d'engloutir un peuple (Goga, 2007: 190) qu'il essayait de dévorer depuis le commencement de la formation de son essence nationale (Drăguicescu, 1995: 277).

l'histoire de Rome leurs traditions, leurs symboles et leurs institutions.

22 Et aussi aux Serbes, Bulgares, Géorgiens, Ukrainiens, Russes et Biélorusses.

23 Les autres populations du royaume sont des Albanais, des Serbes, des Slavons et des Romans.

24 Le peuple Daco-Romain adopta comme langue officielle, liturgique et diplomatique, le slavon qui règne jusqu'au $\mathrm{XVII}^{\mathrm{e}}$ siècle, qu'il s'agisse des manuscrits, des actes juridiques ou des annales nationales. 
L'Église orthodoxe joua un rôle essentiel dans la transmission de la culture slavo-byzantine dans les Pays roumains, notamment par la nomination de métropolites grecs, par le contact avec des moines slaves et les échanges de manuscrits. La symbiose de l'héritage slavo-byzantin et de l'État alors en plein développement politique et économique a donné naissance à une culture slavo-roumaine (Joudiou, 1998:25) Cette assimilation de l'héritage slavo-byzantin et l'usage du slavon, langue de l'Église, de la culture, de l'État par des élites dont la langue vernaculaire était romane, permettent de parler légitimement d'acculturation, selon B. Joudiou. Les invasions qui eurent lieu du $\mathrm{II}^{\mathrm{e}}$ au $\mathrm{VI}^{\mathrm{e}}$ siècles et celles qui se sont succédée par la suite: peuples nomadesturcs d'Asie centrale - Khazars, Petchenègues, Coumans (Iorga, 1920: 65), ouraliens - Magyars ( $\mathrm{IX}^{\mathrm{e}}$ siècle), turcs d'Europe orientale et d'Asie du Nord - Tatars (XIII ${ }^{\mathrm{e}}$ siècle ${ }^{26}$, n'ont pourtant pas réussi à ébranler l'unité culturelle et ethnique des autochtones. Ils n'ont fait que passer ou ont été finalement assimilés puisque la romanité a survécu. Ainsi s'explique la persistance de la langue daco-roumaine - nommée officiellement roumain en Roumanie et moldave en République de Moldova comme attesté au $\mathrm{XVI}^{\mathrm{e}}$ siècle - et de la «race des Daco-Romains» (Costin, 1886:27) - appelés Români (Roumains) ${ }^{28}$ (Ruzé, 1999: 9), aboutissant à la formation d'une nation roumaine (1859) avant la fondation de la Grande Roumanie (1918)29: les premières attestations de ce groupe datant du $\mathrm{XvI}^{\mathrm{e}}$ siècle. C'est en effet en 1532 que l'humaniste italien Francesco della Valle note dans ses récits de voyage à propos des peuples vivant en Transylvanie, Valachie et Moldavie qu'ils se nomment eux-mêmes Roumains: "Romei dans leur langue». Il cite même une phrase en roumain: «Sti Rominest?» («Connais-tu le roumain?») (Isopescu, 1929: 19).

25 http://balkanologie.revues.org/index241.html

26 Tandis que les commerçants de la de la République de Gênes (l'une des grandes républiques maritimes italiennes), qui s'établirent à l'embouchure du Dniestr (le port Akkerman), et aux bouches du Danube (le port Chilia), construisirent, à partir de 1315, la citadelle - la Cité Blanche (Cetatea Albă), sur les bords de la mer Noire et sur le Danube.

27 http://ro.wikisource.org/wiki/De_neamul_moldovenilor

28 L'endonyme români par lequel s'identifiaient les Roumains, ne désignait pas au Moyen Âge une nationalité mais une origine et une langue communes: limba românească.

29 La création de l'État roumain moderne date du XIX ${ }^{\mathrm{e}}$ siècle, et résulte de la réunion des anciennes principautés médiévales: Valachie et Moldavie (1859), et Transylvanie (1918) 


\section{Affirmation de la langue roumaine}

Entre le milieu du $\mathrm{XV}^{\mathrm{e}}$ siècle et les années 1520 , on assiste à une période d'affirmation culturelle des Principautés.

L'introduction progressive de la langue roumaine dans la vie publique, dans la littérature écrite et à l'intérieur de l'Église ${ }^{30}$ a commencé au XII ${ }^{\mathrm{e}}$ siècle par la pratique irrégulière de l'écriture dans certains domaines de la vie publique et elle s'est achevée au début du XVIII ${ }^{\mathrm{e}}$ siècle par une généralisation de l'utilisation de la langue roumaine ayant les caractéristiques d'une véritable réforme, avec des conséquences importantes sur l'évolution et la configuration de la langue. Selon Silași G., c'est déjà vers l'année 1100 ap. J.-C., que «les Roumains de Dacie ont traduit la liturgie du slavon dans leur langue nationale» et que le prince Petru I al Moldovei (Pierre Ier de Moldavie), 1375-1391 dépose le 12 septembre 1387 son serment de vassalité au roi de Pologne, Ladislas II Jagellon, dans «sa langue roumaineparce qu'il ne connaissait pas d'autre langue» (Silaș, 1879: 87). L'auteur I. Gheție mentionne que l'époque du pape Inocențiu le IV siècle (1243-1258) est liée à un événement: la traduction de la liturgie en langue roumaine (Ghetie, 1974: 13) mais que les Roumains utiliseront l'alphabet cyrillique jusqu'à leur adoption de l'alphabet latin en 1860 (Moceanu, 2002: 61). Pour des raisons diverses parmi lesquelles se trouve l'utilisation officielle du slavon par les églises et les chancelleries, le plus ancien texte roumain noté en alphabet cyrillique (Chițimai, Toma, 1984: 32), la Lettre ${ }^{31}$ du marchand Neacșu L. ${ }^{32}$ de Câmpulung-Muşcel adressée au maire du județ (région) ${ }^{33}$ Brasov Hanăș Bengner, date de 1521. Ce document s'intègre dans l'historique des relations très étroites entre les marchands saxons (saşi) de la ville de Brasov et ceux de Valachie et Moldavie ${ }^{34}$.

Aussitôt après cet événement, l'utilisation de la langue roumaine devient plus fréquente. Depuis 1508, année où le moine serbe Macarie (Danilov,

30 La plus ancienne information nous renvoie à l'époque du pape Inocențiu IV (12431258). Elle est liée à l'événement de la traduction de la liturgie en langue roumaine.

31 http://www.cimec.ro/istorie/neacsu/rom/scrisoare.htm

32 Découverte par Friedrich Stenner en 1894 dans les Archives Nationales du județ Brasov, Roumanie (se réfère aux mouvements militaires Ottomans sur le Danube).

33 Du latin: judicium. C'est une division administrative, l'équivalent des régions françaises.

34 Dans ce texte, la principauté nommée par les étrangers "Valachie» est appelée Țara Românească (Terre roumaine). Comme dans le cas de l'ethnonyme «roumain», la graphie du nom du pays n'est pas encore fixée, jusqu'au début du XIx ${ }^{e}$ siècle, les textes présentent les deux formes: Țara Românească et Țara Rumânească. 
2011 : 68) fonde la première typographie (il imprime un missel ${ }^{35}$, en slavon, au monastère Dealu, Principauté de Valachie), nous pouvons parler d'un début d'activitétypographique en Roumanie (Andreescu, 2007: 10). Ultérieurement, l'art de l'imprimerie sera lié au nom d'un traducteur typographe valaque, le diacre Coresi (Moceanu, 2002: 68) dans les principautés de Valachie et de Transylvanie ainsi qu'aux efforts des métropolites moldaves, Varlaam et Dosoftei dans la principauté de Moldavie. Vers 1556, Coresi fait paraître des livres en slavon et les premiers ouvrages en langue roumaine ${ }^{36}$ (fait impossible à telle époque en Valachie), traduits par lui-même ${ }^{37}$. Ses travaux répandus dans les régions roumaines ont été utilisés à la fois à l'église et à l'école. C'est le premier signe de réorientation vers l'abandon progressif $\mathrm{du}$ slavon en faveur du roumain. Ces imprimés considérés comme des monuments de roumain ancien, sont importants aussi parce que dans leurs préfaces, Coresi relève pour la première fois, le problème de l'introduction de la langue roumaine dans le culte religieux et montre qu'ils ont joué un rôle dans l'évolution et l'unification de la langue. Par exemple, l'épilogue de son ouvrage Tetraevanghelul cite le nom de Hanăș Bengner en le présentant comme un partisan des écrits en roumain «[...] mieux vaut dire cinq mots dont on comprend le sens plutôt que dix mille mots incompréhensibles en langue étrangère».

Le déclin du slavon comme langue des érudits, comme langue sacrée ainsi que son abandon par les Roumains est signalé par Dimitrie Cantemir qui s'est manifesté comme le premier slavophone roumain. Il a stigmatisé le slavonisme culturel des Roumains comme une période de barbarie. Dans son livre Descrierea Moldovei (Description de la Moldavie), il consigne des détails très intéressants sur l'éducation intellectuelle des jeunes nobles roumains: «la seule langue qu'on leur faisait apprendre était le slavon», lequel était «la langue de la chancellerie comme de l'Église roumaine nécessaire à la lecture de la Sainte Écriture» (Cantemir, 2001: 12) considéré par lui comme une langue étrangère, dont «les formes contrastaient avec le fond latin de l'expression de la culture latine» (Georgescu, 1992: 130). Cantemir affirme que les Roumains ont utilisé l'alphabet slavon à l'époque d'Alexandru cel Bun (1400-1432) et fait l'éloge de Vasile Lupu, premier voḯvode (principe)

35 Livre liturgique contenant toutes les informations concernant les chants, lectures, prières d'une messe.

36 Utilisant le parler de Valachie et Transylvanie dans les ouvrages Întrebare creștinească (connu sous le nom de Catéchisme, 1559 et Tetraevanghelul, 1561).

37 La traduction du Nouveau Testament des quatre Évangiles: Liturghierul, Psaltirea (1570). 
de Moldavie (1634-1653) à introduire la langue roumaine dans l'Église et les écoles pour une courte période qui a commencé à sortir progressivement la Principauté de Moldavie de l'obscurité dans laquelle l'avait noyée le slavonisme.

Comme nous l'avons remarqué plus haut, en Moldavie, les arguments scripturaires apparaissent dans les impressions des hauts hiérarques orthodoxes moldaves, fondateurs de la première typographie en $1640^{38}$ : les métropolites Varlaam (1580-1657) et Dosoftei (1624-1693) qui assument la traduction du grec, du slavon et l'impression des textes religieux en introduisant la langue roumaine dans l'Église Orthodoxe (le processus sera achevé vers 1715). Ces traditions littéraires locales reflétaient les normes linguistiques dialectales des régions où elles ont été produites et correspondaient aux parlers daco-roumains les plus importants du sud ${ }^{39}$ et $\mathrm{du}$ nord ${ }^{40}$. La nécessité de renoncer aux particularités régionales en faveur d'un principe de compréhension des textes imprimés par tous les Roumains est formulée par le Métropolite de Transylvanie Simion Ștefan dans sa Préface au Nouveau Testament de Bălgrad (Alba-Iulia), 1648. Les différences dialectales des diverses régions y sont constatées et le besoin de construire une langue écrite commune et accessible à tous les Roumains y est affirmé. Le manque d'unité du roumain écrit a maintenu les traditions littéraires régionales jusqu'à la deuxième moitié du XviII siècle. Quand se produit la réforme de la langue littéraire réalisée dans le cadre de la culture ecclésiastique, l'unification de l'ancien roumain littéraire imposée comme norme unique au niveau des textes imprimés, est devenue unitaire pour les Roumains de Moldavie, Valachie et Transylvanie.

Le premier écrit de la littérature roumaine ${ }^{41}$ qui se distance du style ecclésiastique, est la chronique de G. Ureche, Letopisețul Țării Moldoveit2. Ce texte note que la langue parlée par les Moldaves est la même que celle des Valaques et que Moldaves, Valaques, Transylvains appartiennent au même groupe ethnique (Ureche, 1998: 13). Ces idées à la source de la montée du nationalisme roumain $\mathrm{du} \mathrm{XVIII}^{\mathrm{e}}$ siècle, seront développées plus tard par une grande personnalité de la culture orientale, l'humaniste et philosophe

38 Dans la capitale de la Principauté de Moldavie, la ville Iași (Iassy).

39 Oltéan, monténien et dicien.

40 Banatéen, transylvain, maramuréchois et moldave.

41 L'auteur a rencontré des difficultés d'expression parce qu'il n'avait pas eu de modèle de chronique en roumain, c'est pour cela que les phrases sont lourdes, mélangeant la syntaxe slave et celle du roumain oral.

42 L'ouvrage constitue le début de l'historiographie en langue roumaine. 
roumain D. Cantemir, dans son œuvre encyclopédique, contenant des descriptions de nature géographique, politique, administrative, économique, sociale, ethnographique et linguistique de la Moldavie Descrierea Moldovei ${ }^{43}$ (1716). Il tente d'y démontrer qu'en dépit de la division en provinces séparées, les populations de ces pays ont une même origine, parlent la même langue ${ }^{44}$, qu'elles représentent par conséquent une seule et unique entité ethnique et nationale (Boca-Bordei, 2002: 509). L'idée de l'identité du peuple et de la langue parlée par les Roumains de partout est clairement exprimée par G. Călinescu dans son Istoria literaturii române de la origini până în prezent (Histoire de la littérature roumaine des origines à nos jours), «[...] le peuple roumain et la langue roumaine parlée entre le Danube, la Tisa (Tisza) et le Dniestr représente une unité introuvable ailleurs [...]» (Călinescu, 1997: 19).

\section{La Principauté de Moldavie: chemin vers la fusion}

La communauté de langue (autour du roumain) et de traditions culturelles, auxquelles s'est ensuite ajoutée celle de la religion (latine initialement, byzantino-orthodoxe ensuite) ont constitué les prémisses de la réunion des principautés dans les futurs États souverains. Les Roumains n'ont constitué des États qu'à partir du XIV e siècle (Aramă, 2003: 29) avec la création des principautés de Valachie ${ }^{45}$ et de Moldavie ${ }^{46}$ qui étaient une fédération de cnezate (duchés) ${ }^{47}$ situés entre les montagnes Carpates, le fleuve Dniestr et la mer Noire.

La Principauté de Moldavie fut probablement nommée ainsi d'après le nom de sa première capitale, Moldvàr (nommée aussi: Târgul Moldovei).

43 Une œuvre monumentale, considérée l'une des études historiques les plus importantes $\mathrm{du} \mathrm{XVIII}^{\mathrm{e}}$ siècle, dont le manuscrit original se trouve à la Bibliothèque Nationale à Paris.

44 L'auteur a présenté des conceptions théoriques détaillées sur les questions linguistiques, affirmant que «la variété de la langue des Moldaves, parue autour de Iași, est plus propre, étant donné le contact permanent des habitants autour de la capitale avec le milieu élevé de la cour royale qui se sont cultivés eux-mêmes et la langue qu'ils parlent «le discours moldave est littéraire par lui-même».

45 Elle couvrait le sud de la Roumanie actuelle, avec les Carpates au nord, et sa frontière sur le Danube avec la Bulgarie.

46 Ces principautés s'organisent pratiquement autour de leurs princes et de leurs assemblées d'État, composées de boyards, du clergé et parfois de paysans libres, ainsi que de marchands.

47 Ce regroupement au XIV ${ }^{\text {e }}$ siècle des cnezate moldaves qui étaient vassaux de la Galicie ou des Tatars au XIII ${ }^{e}$ siècle, est parallèle à celui qui a lieu dans la Valachie voisine, dont les cnezate étaient vassaux de la Hongrie. 
Selon deux autres hypothèses, le nom de la principauté dériverait de l'ancien allemand $M$ ulda ${ }^{48}$ qui signifie «mine» (Iorga, 1920:49). En effet, des carrières y étaient exploitées par des maîtres allemand ${ }^{49}$. Mais la première référence au nom de Moldavie est mentionnée au XIV ${ }^{\mathrm{e}}$ siècle comme fief de Dragoş Vodă (appelé aussi: Dragoş de Bedeu), prince transylvain vassal du roi de Hongrie, la première figure fondatrice de Moldavie dépendant de la Hongrie (il fut prince de Moldavie entre 1351 et 1353) à établir sur ce territoire une ligne de défense pour renforcer l'influence hongroise face aux Tatars et aux Galiciens ${ }^{50}$. Il existe à ce sujet une légende populaire assez poétique (Cantemir, 2001 : 15) contant que Dragoş qui chassait dans les régions à l'Est de la chaîne des Carpates, aurait eu une chienne nommée Molda (Ureche, 1998: 10). La chienne tombant sur un bœuf sauvage (portant une étoile au front) se serait noyée dans la rivière désormais appelée Moldova (Costăchel, Panaitescu, Cazacu, 1957: 37). Ce qui conduisit alors Dragoş à donner ce nom ${ }^{51}$ à la principauté qu'il établit. C'est en souvenir de cette heure solennelle que la tête de l'aurochs tué par le prince qui avait guidé ses pas vers la Moldavie (Pittard, 1917: 157) est inscrite dans les armoiries actuelles de la Roumanie et de la République de Moldova.

Mais en 1359, les Moldaves, mécontents de la domination hongroise s'unissent contre Dragoş et lui préfèrent Bogdan Întemeietorul (Bogdan Ier le Fondateur, 1359-1365). Originaire à son tour de Transylvanie mais opposé à la suzeraineté hongroise, il force les Mongols à se retirer à l'Est du fleuve Dniestr, il renforce la position de la Principauté de Moldavie, assurant son indépendance ${ }^{52}$. Une fois l'indépendance de la Couronne hongroise conquise dans la bataille, la Principauté s'est consolidée économiquement, s'est mieux organisée politiquement, militairement et s'est de plus en plus développée démographiquement au point qu'elle finira par s'inscrire sur la carte de l'Europe sous la forme d'un pays souverain.

La Moldavie devient État indépendant à l'époque du voiévode Alexandru cel Bun (Alexandre ${ }^{\text {er }}$ le Bon, 1400-1432) et elle délimite ses frontières naturelles : Danube et mer Noire au Sud, Dniestr à l'Est, Pologne au Nord. La

48 Nous trouvons Mulda en Saxe et en Bohème.

49 Venus du Rhin moyen et inférieur.

50 Une région historique de l'Union de Pologne-Lituanie.

51 Nommer une ville d'après le nom de la rivière qui la traverse est une habitude fréquente dans les territoires habités par les Roumains.

52 La fédération de cnezate devient alors un Voïévodat gouverné par des Voïévodes, tandis que les anciens cnezate deviennent des comtés (ținuturi), gouvernés par les grandes familles de boyards. 
sortie de la Moldavie hors de la sphère d'influence ${ }^{53}$ de la politique polonolituanienne (Epure, 2007: 57) a été le principal objectif de son installation sur le trône de la Principauté.

Alexandre Ier le Bon a compris la gravité de la situation dans laquelle il se trouvait et il a choisi une voie favorable pour son pays dans les problèmes de nature économique ${ }^{54}$, religieuse. Il va jeter les bases de l'organisation de l'Église de Moldavie, obtenant la reconnaissance de la Métropolie de Moldavie par le Patriarcat œcuménique de Constantinople et de politique externe (Cihodaru, 1984: 170).

Mais ces premières formes étatiques et leur avenir sont à nouveau confrontés à de sérieuses menaces extérieures. Les principautés roumaines doivent d'abord échapper à la tutelle hongroise puis se défendre contre la Pologne, et enfin, accepter de payer un tribut annuel à la Porte Ottomane dès $1456^{55}$ - condition nécessaire à l'établissement de la paix - pour échapper à l'occupation de leurs territoires. Le fardeau le plus lourd de la souveraineté ottomane n'était pas politique, mais économique.

L'autonomie moldave a été toutefois de courte durée. En 1453, année de la chute de Constantinople, les Turcs musulmans, alliés aux Tatars de Crimée, attaquent la Moldavie.

À la suite de ces constatations historiques, le philosophe roumain, Mircea Eliade concluait dans Os Romenos latinos do Oriente:

«Les seigneurs de Moldavie [...]» parmi lesquels le voïévode Etienne le Grand (Ștefan cel Mare), 1457-150456, sous le règne duquel la Moldavie a connu sa plus grande extension, «[...] ont édifié une série de forteresses sur les bords du Dniestr, orientées vers l'Orient; ces bastions défendaient la frontière du nouvel Etat chrétien contre les nomades des steppes $[\ldots] \|^{57}$. Les

53 Par le traité signé à Lublau, le 15 mars 1412, entre le roi de Pologne, Ladislas II Jagellon, et le roi de Hongrie, Sigismond Ir du Saint-Empire, ce dernier s'interdit de troubler l'exercice de la suzeraineté polonaise sur la Moldavie; ce qui met fin aux prétentions de la Hongrie dans ce domaine.

54 Par le privilège douanier du 4 oct. 1408, le prince régnant moldave donnait aux commerçants de Lviv (Lvov) la liberté de vendre et d'acheter en Moldavie, d'aller avec leurs marchandises en Transylvanie, en Valachie, en Turquie.

55 Suite à une campagne navale sur les bouches du Danube, les Ottomans alliés aux Tatars soumettent le littoral moldave. Le voïévode de Moldavie Petru III Aron (de 1451 à 1452, puis de 1454 à 1455 et de 1455 à 1457) reconnaît la suzeraineté des Turcs et doit payer un tribut annuel de 2000 ducats d'or au sultan ottoman Mehmed II le Conquérant.

56 En dépit de ses victoires militaires significatives contre les envahisseurs hongrois, polonais, tatars, la Moldavie cédera à la puissance Ottomane en 1538, restant sous domination des Turcs pendant les 300 années à venir.

57 À savoir, les Tatars, entre 1359 et 1789. 
seigneurs moldaves sont entrés dans l'histoire moderne avec une splendide mission «[...] défendre la civilisation et la chrétienté latino-occidentale contre les menaces turco-slaves» (Eliade, 1943: 11).

Le territoire compris entre les fleuves Prut et Dniestr, au sein de la principauté de Moldavie, très exposée aux raids permanents, est défendu par la chaîne de cités de défense, composée de la Cité Blanche ${ }^{58}$, de la fortification de Tighina ${ }^{59}$, de la citadelle Soroca (dont les premières fortifications datent des Daces) ${ }^{60}$ et de la cité de Hotin ${ }^{61}$. Eliade a également souligné l'importance de la mission historique de la Moldavie dans la défense de l'Europe chrétienne contre les invasions extérieures, le fleuve Dniestr ayant été et continuant d'être considéré par les historiens comme la frontière géographique (naturelle) de l'Est de l'Europe.

Comme l'écrivait dans son histoire de la Moldavie Grigore Ureche, ce pays qui se trouvait "[...] sur le chemin de toutes les mauvaises actions" s'étendait «des montagnes [Carpates] jusqu'au Dniestr et en bas jusqu'où le Danube verse ses eaux dans Vidov et jusqu'à La Cité Blanche et Chilia, Reni, Dniestr en haut jusque plus haut que Tchernovtsy [...]» (Ureche, 1998: 25) qui correspond à la Moldova actuelle, sans la région de Bougeac (Boudjak) ${ }^{62}$, menait une vie extrêmement difficile, marquée par une implacable géographie.

58 Située à l'embouchure du Dniestr, cette position lui confère une importance stratégique évidente. Elle a été attestée, tant d'un point de vue historique que géographique, depuis l'antiquité, et tout d'abord, comme une position construite par les Grecs de Milet, et s'appelait Tyras, d'après le nom antique du fleuve (du vi ${ }^{\mathrm{e}}$ siècle av. J.-C. au $\mathrm{I}^{\mathrm{er}}$ siècle), puis comme une position romaine ( $\mathrm{du} \mathrm{I}^{\mathrm{er}}$ au IV $\mathrm{V}^{\mathrm{e}}$ siècle de notre ère).

59 La forteresse de Tighina est mentionnée, pour la première fois, le 8 octobre 1408, dans un privilège (document écrit en vieux slave oriental) accordé par le voiévode moldave Alexandre Ir le Bon aux commerçants de Lviv, comme un poste de douane moldave (situé sur l'une des routes commerciales transeuropéennes liant la mer Baltique et la mer Noire).

60 La cité de Soroca est mentionnée par une tradition historique comme une forteresse génoise, en lieu et place d'une colonie grecque. À la fin du vi $\mathrm{I}^{\mathrm{e}}$ siècle, la cité de Soroca apparaît comme un point de résistance, un point stratégique de défense contre les Turcs, les Tatars et autres envahisseurs.

61 Construite au IX ${ }^{\mathrm{e}}$ siècle, elle a été reconstruite en 1325, par des voïévodes moldaves, grâce à l'argent apporté par les marchands génois de la mer Noire. Elle était située sur la route commerciale transeuropéenne reliant la Pologne aux bords de la mer Noire et du Danube, mais aussi Kiev à la Hongrie, ainsi que les basses terres de Polésie (aujourd'hui partagée entre la Pologne, la Biélorussie et l'Ukraine) au Dniestr.

62 C'est une région multiethnique sur les bords de la mer Noire entre le Danube et le Dniestr, au sud de la République de Moldavie. Aujourd'hui, elle fait partie de l'oblast d'Odessa en Ukraine. 
C'est sur le même ton que s'exprime Dimitrie Cantemir dans Hronicul vechimii româno-moldo-vlahilor (L'historique de l'ancienneté des Roumanomoldo-valaques), révélant le rôle des sacrifices que «le peuple roumain porteur de la culture latine à l'Est de l'Europe» (Cantemir, 1981:21) a joué dans la défense de la civilisation européenne. De notre temps, cette œuvre de D. Cantemir est plus actuelle que jamais, elle offre un point d'appui fiable pour la défense de notre identité nationale, de la langue roumaine et de l'histoire nationale de survivance du peuple roumain.

C'est à ce prix que les Principautés moldave et valaque ont sauvegardé leur autonomie relative, en préservant leur entité d'État, leurs propres structures politiques, militaires et administratives, leurs lois, leur organisation sociale, tout en conservant une certaine autonomie sous leurs princes autochtones (élus soit par leur peuple, soit par les boyards, mais recevant leur investiture de la Sublime Porte) ${ }^{63}$ ainsi que la possibilité de poursuivre leur développement culturel ${ }^{64}$ à l'abri de l'islamisation forcée ou des bouleversements démographiques pratiqués dans d'autres régions balkaniques.

Les princes établissent leurs capitales: Bucarest $(1698)^{65}$ pour la Principauté de Valachie et Iași (1564-1862) ${ }^{66}$ pour la Principauté de Moldavie, puis plus tard, Bucarest (1862) pour les Principautés unies de Valachie et de Moldavie (le Vieux Royaume). Les échanges économiques, le développement de villes à villes, liées au monde commercial par des itinéraires de transit, ont offert une bonne chance aux formations politiques roumaines une bonne chance de placer leurs projets d'unification sur une base viable.

63 Dès le $\mathrm{xv}^{\mathrm{e}}$ siècle, les principautés sont en présence de la résistance face aux Ottomans, lancée par les voḯvodes autochtones Mircea cel Bătrân (1386-1418) en Valachie, Iancu de Hunedoara (1441-1456), en Transylvanie et Ştefan cel Mare (1457-1504) en Moldavie.

64 Les Roumains se sont repliés vers la culture et les objets d'art, dont la valeur artistique a été reconnue dans le monde entier. Des palais princiers ont été construits à CâmpulungMuşcel, Curtea de Arges et Târgovişte dans Valachie, à Suceava et Iaşi dans Moldavie, à côté d'un certain nombre de villes de défense (Poienari, Cetatea Neamțului, Suceava, Chilia, Cetatea Albă), et de beaux monastères (Tismana, Cozia, Dealu, Curtea de Arges, Neamț, Putna, Voroneț, Sucevița).

65 La première capitale de la Valachie a été Câmpulung (1330), la deuxième Curtea de Argeș (1348), la troisième Târgoviște (1369). La ville de București a été désigné comme capitale par le prince Constantin Brâncoveanu (Constantin Brancovan).

66 La première capitale de la Principauté de Moldavie a été la cille Baia (1359-1564). 


\section{Symboles de l'unité nationale}

Le XIx ${ }^{e}$ siècle, marqué par l'affirmation de l'idée nationale en Europe, se caractérise dans l'espace roumain par des actions politiques ayant deux buts: l'émancipation de la souveraineté turque et la constitution d'un État de tous les Roumains. Un des moments forts dans l'histoire roumaine a été marqué par le pouvoir de Mihai Viteazul (Michel Ier le Brave) (Giuescu, 2000: 307), premier prince de Valachie (1593-1601) à réussir à unifier ${ }^{67}$ en 1600 pour un court laps de temps ${ }^{68}$, tous les pays habités par des Roumains, à savoir les trois principautés historiques, Transylvanie, Valachie et Moldavie à l'origine de la Roumanie moderne. Devenu symbole de l'unité nationale, il réveille la conscience roumaine et les générations suivantes adoptent l'idée d'un État unitaire et indépendant roumain sur l'espace de l'ancienne Dacie.

Sans tenir compte de la formation d'État dans laquelle ils vivaient, les Roumains ont toujours affirmé leur appartenance au même peuple. La conscience de leur communauté de langue, de foi, de traditions et d'habitudes a été plus intensément cultivée sur le plan culturel par les écrits des premiers historiens, appelés chroniqueurs.

La pensée ethnologique roumaine voit ainsi le jour comme mise en œuvre de cette identité de longue durée, à l'origine et au cœur même de la nation. On peut invoquer à ce titre les chroniqueurs du XVII ${ }^{\mathrm{e}}$ siècle et surtout le prince Dimitrie Cantemir qui, au début du XviI ${ }^{\mathrm{e}}$ siècle, s'attaque le premier au slavon - langue officielle de l'orthodoxie - qu'il considère comme étrangère et barbare. Il considère que le patriarche Teoctist, bulgare d'origine, aurait imposé le slavon comme langue de culte au $\mathrm{xv}^{\mathrm{e}}$ siècle afin d'éloigner les Roumains de l'Occident. C'est ainsi que pour Cantemir, Teoctist est le premier responsable de la barbarie dans laquelle la Moldavie se trouve noyée à présent. L'identité roumaine ayant ainsi tourné le dos aux Balkans, la construction identitaire va s'orienter vers Rome et vers l'origine latine du peuple roumain.

Nous trouvons les premières références explicites à un «territoire ethnolinguistique roumain» comprenant la Valachie, la Moldavie et la Transylvanie, dans l'ouvrage De neamul moldovenilor, din ce țară au ieșit strămoşii lor (Sur la race des Moldaves, le pays duquel viennent leurs

67 Prenant le titre de prince de Valachie, de Transylvanie et de Moldavie.

68 Mais les grands pouvoirs de l'Autriche, l'Empire ottoman et la Pologne n'ont pas favorisé une telle politique, pour que l'union soit de courte durée. 
ancêtres) du chroniqueur Miron Costin: «[...] ce peuple est roumain. Tant qu'ils ont vécu, ce nom ils ont toujours porté [...]» (Costin, 1886:69).

Toutes ces périodes de crise de l'histoire des Principautés contribuent à la fin du XVIII ${ }^{\mathrm{e}}$ et au début du XIX ${ }^{\mathrm{e}}$ siècles, à la formation de la conscience nationale roumaine. La notion d'une communauté territoriale, économique, linguistique et culturelle existe de part et d'autre des Carpates. Toutes les institutions culturelles de Valachie, Moldavie et Transylvanie s'emploient à répandre cette notion dans des milieux de plus en plus larges. Cependant, l'idée d'unification a été gardée vivante et a donné une nouvelle impulsion à la lutte des Roumains pour l'installation d'un État national indépendant. Ces trois entités étatiques vont tracer leur chemin entre les influences des puissances voisines, la Turquie, la Russie et l'Empire austro-hongrois et vont finalement accéder vers le milieu du $\mathrm{XIX}^{\mathrm{e}}$ siècle à l'union politique dans le cadre de l'émergence de l'État national.

En 1821 et en $1848^{70}$ (connue commel'année des révolutions européennes), des soulèvements nationalistes infructueux furent réprimés par la Turquie et par la Russie, qui se glorifiait de protéger les orthodoxes du sultan musulman. Dans le contexte d'émergence des identités nationales en Europe, notamment pendant la période appelée «le siècle des nations", les révolutionnaires roumains exilés en Occident ont propagé l'idée de la réunion des deux principautés de Moldavie et de Valachie dans un seul État, donc de la constitution de l'espace roumain en mettant en avant l'intérêt pour l'Europe de stabiliser cette aire géographique.

Ils «[...] montrèrent à l'Europe qu'ils nourrissaient des aspirations toujours contrecarrées auparavant par le protectorat russe», ils «[...] soutenaient dans leurs écrits que les Roumains étaient un peuple d'origine latine, frères des Français, des Italiens, des Espagnols et Portugais et qu'ils poursuivaient aussi un idéal national qui tendait à l'union de tous les Roumains dans une seule patrie $[\ldots] »$ (Xenopol, 1908: 81). Ils réussirent à «[...] convaincre l'opinion publique européenne que ce peuple tâchait de toutes ses forces de se soustraire à leur désastreuse influence, aimant mieux rester sous la sauvegarde de son ancien suzerain, l'Empire ottoman» (Xenopol, 1908: 82).

Ils ont su trouver un allié important en la personne de Napoléon III, qui visait une Europe des nations sous direction française. Pour y arriver, il s'était allié aux Anglais, qui avaient tout intérêt à restreindre l'influence russe en Orient. À l'époque, les guerres russo-turques survenaient avec une régularité

69 http://ro.wikisource.org/wiki/De_neamul_moldovenilor

70 Cette révolution avait tendu à émanciper les Roumains de la tutelle russe. 
impressionnante mais en 1853, l'Angleterre et la France s'inquiétaient de l'expansionnisme russe en Europe. La Russie sera vaincue lors de la Guerre de Crimée (1853-1856), ce qui provoqua un premier remaniement des frontières lors du Congrès de Paris (le 30 mars 1856): les départements de Cahul, Bolgrad et Ismaïl redevinrent moldaves, des frontières définitives furent fixées entre la Russie et la Moldavie le 6 janvier 185771. À ce congrès, les puissances ont aussi décidé du destin de la Valachie, de la Moldavie, du projet d'union des principautés avancé par le gouvernement de Napoléon III et par Camillo Benso, comte de Cavour ${ }^{72}$ au nom du principe des nationalités appuyé par la Russie dans le but d'affaiblir la Turquie (Sturdza, 1971: 247). Une des clauses du traité de Paris du 30 mars 1856 a eu pour but de retirer à la Russie le protectorat sur ses régions (Xenopol, 1908: 82) et de l'attribuer à l'Europe entière. Le 19 août 1858, la Russie signait conjointement avec la France, l'Angleterre, la Prusse, l'Autriche, la Turquie et la Sardaigne, la Convention pour l'organisation des principautés maintenant la suzeraineté de la Porte mais garantissant leur autonomie interne et leur droit de s'administrer en dehors de toute ingérence étrangère.

C'est avant la création de l'État moderne que commence vraiment l'affranchissement des Roumains, que les termes de "Roumain », de "langue roumaine ${ }^{73}$ en accord avec les aspirations des Roumains même, sont transformés par le Français Élisée Reclus dans sa Géographie universelle ${ }^{74}$ en endonymes internationalement acceptés.

Les turbulences s'apaisent quand, en 1859, les principautés de Valachie et de Moldavie (moitié occidentale située entre les Carpates et le Prut) élisent toutes deux comme prince Alexandru Ioan Cuza (Alexandru Ioan Ier) (Matei, Nicolae, Negut, Radu, 2005: 21) : ce dernier réalise de facto leur unification. L'acte historique d'unité politique entre la Valachie et la Moldavie occidentale en un seul Etat, daté du 24 janvier 1859 (ancien style ${ }^{75}$ )

71 Autant dire que le nouveau tracé obtenu lors du Congrès de Paris était loin de satisfaire la Russie.

72 Homme politique et acteur de l'unité italienne.

73 Attestés à partir du XIV ${ }^{e}$ siècle, les termes "Roumains» et "roumain" désignaient en roumain les habitants et la langue de la Transylvanie, de la Valachie et de la Moldavie, ainsi que des régions voisines. Mais ces termes sont restés des endonymes jusqu'au $\mathrm{XIX}^{\mathrm{e}}$ siècle, tandis que l'exonyme désignant les Roumains à l'étranger était «Valaques" (mais également «Moldo-Valaques» ou «Moldaves»).

74 http://www.gutenberg.org/files/28370/28370-h/28370-h.htm\#footnote1

75 Le calendrier julien est signalé par l'appellation ancien style (a.s.). Certains événements de l'époque étaient datés parfois selon le calendrier julien (dit «ancien style»), parfois selon le calendrier grégorien ( dit nouveau style»). 
a d'une part affirmé de facto leur autonomie ${ }^{76}$, d'autre part transformé un rêve séculaire en réalité, «ce qui traduisait bien la volonté effective de rétablir une ancienne identité, jusque-là impossible à affirmer" (Vilaldach, 1999:77). L'Eglise orthodoxe roumaine proclame aussi son autocéphalie malgré la réticence du Patriarche de Constantinople qui ne l'acceptera qu'en 1885. Le 11 décembre (a.s.) 1861, Alexandru Ioan Cuza, souverain des Principautés unies de Valachie et de Moldavie (ayant des gouvernements et des assemblées séparés à cette date) a publié la proclamation affirmant que la nationalité roumaine était fondée ${ }^{78}$. Le 22 janvier (a.s.) 1862 a été créé le premier gouvernement unitaire roumain et le 24 janvier (a.s.) 1862, les deux principautés fusionnent officiellement pour former les Principautés unies de Roumanie, ce qu'on appelle en Roumanie le Vieux Royaume - territoire couvert par le premier état-nation indépendant réunissant des populations de langue romane (le roumain moderne) -, avec pour capitale la ville de Bucarest. L'indépendance du pays est reconnue au Congrès de Berlin en 1878. Les princes Mihai Viteazul et Alexandru Ioan Cuza représentent tous deux une charge symbolique significative associée à l'idée d'union et d'unité nationales, à travers les moments de 1600 et 1859.

À partir de cette date, la Principauté de Moldavie a cessé d'exister. Historiquement, l'État roumain moderne s'est formé sans la moitié orientale de la Principauté de Moldavie, région située entre le Prut et le Dniestr, nommée Bessarabie (aujourd'hui, la République de Moldova), car celle-ci était à cette époque - en 1812 - incluse dans l'Empire russe (Cașu, 2000: 10). Ce n'est qu'en 1918 que la Roumanie et la Moldova actuelles ont formé un État commun (la Grande Roumanie).

Puis au début du XviII ${ }^{e}$ siècle, la partie orientale de la Principauté de Moldavie cherche à se libérer de l'occupation ottomane.

76 L'unité de fait fut officiellement reconnue en 1861 par les puissances européennes et par les Turcs. Le 20 novembre (a. s.) 1861, la Porte ottomane a adopté le Firman sur l'organisation administrative de la Moldavie et la Valachie par lequel il a admis l'unification politique et administrative des principautés de Moldavie et de Valachie, des territoires autonomes qui étaient dans la composition de l'Empire ottoman.

77 http://www.regard-est.com/home/breve_contenu.php?id=592

78 Sur le plan politique, Cuza n'obtiendra pas l'assentiment des masses populaires et paysannes, qui lui reprochaient son idéologie libérale et occidentale. 


\section{Protectrice de la civilisation européenne}

$\mathrm{Au} \mathrm{XVIII}^{\mathrm{e}}$ siècle, la Principauté de Moldavie joue le rôle d'État-tampon entre l'Empire ottoman et une nouvelle puissance qui se fixe au bord de la mer Noire: la Russie. À cette époque est enregistrée la tentative du Prince moldave Dimitrie Cantemir ${ }^{79}$ (en 1693, et de 1770 à 1711) de se libérer de la domination ottomane.

Après la défaite de l'armée russo-moldave à Stălinești sur le fleuve Prut, en 1711, «[... ]'Empire ottoman s'approprie le droit de nommer les hospodars au trône du pays» (Galben, 2003: 49). Le nouveau système de gouvernement a été désigné dans la littérature comme «[...] turco-phanariote du fait que les marchands et les usuriers grecs du quartier Phanar d'Istanbul étaient souvent nommés comme hospodars [...]» (Galben, 2003: 49) dans le but de retirer de cette fonction des profits économiques maximums et de renforcer la dépendance politique de la Porte.

Dimitrie Cantemir considérant que la Moldavie ne résisterait aux Turcs qu'avec l'aide de la plus puissante force chrétienne de l'Est de l'Europe (Smeu, 1997: 218-219) conclut avec Pierre le Grand le 13 avril 1711, le Traité d'alliance de Loutsk (Luțk) selon lequel la Moldavie passait sous protection russe, les Russes s'engageant d'abord à soutenir la Moldavie contre l'Empire ottoman «dans la lutte pour la liquidation de la souveraineté turque» (Cantemir, 2001: 9). Ils s'engageaient aussi à ne pas s'ingérer dans sa politique étrangère et ses affaires internes politiques ou juridiques, mais aussi culturelles et linguistiques, la Moldavie restant pleinement souveraine. L'occupation de la Principauté par le Tsar russe (Ghibu, 1997: 30) considérée comme provisoire était censée organiser la défense du peuple roumain, des Principautés et de la Moldavie indépendante gouvernée par la famille des Cantemir sous le protectorat de la Russie (Ciobanu, 1924: 47). Par ce traité, Cantemir demandait l'indépendance et l'intégrité territoriale de la Moldavie, précisant toutefois que la frontière entre les deux pays était fixée sur le Dniestr et il établissait des relations entre la Russie et la Moldavie ${ }^{80}$.

Obligé de se réfugier en Russie, «il a continué de vivre dans le monde d'où il était parti [...]». Comme «ses intérêts visaient la Moldavie, le peuple

79 C'est à l'époque du prince moldave Dimitrie Cantemir - vedette des salons de Berlin à Saint-Pétersbourg - que l'existence d'un État moldave fut largement reconnue par la communauté internationale.

80 Le cantonnement des garnisons russes a été autorisé sur le territoire de Moldova uniquement pendant la guerre. L'achat de terrains et le transfert sur ce territoire des paysans serfs issus de l'Empire russe étaient interdits aux propriétaires terriens russes. 
roumain» (Tofan, 2008:81), il a maintenu des contacts permanents avec la Principauté et agi systématiquement dans l'espoir de reconquérir le trône de ce pays. La vie, l'œuvre, le discours identitaire de D. Cantemir ont par la suite joué un grand rôle dans l'espace public bessarabien.

L'entente entre Dimitrie Cantemir et le tsar Pierre le Grand atteste que la Russie considérait toute la Moldavie ${ }^{82}$ comme sa propre zone d'influence. La Russie transformée en grande puissance européenne ${ }^{83}$ par Pierre le Grand, entre aussi dans le jeu géostratégique dont la mer Noire et le Delta du Danube sont l'enjeu: elle a d'ailleurs lutté durant des siècles pour atteindre ce but jusqu'à l'annexion définitive de 1812. L'ancien prince moldave, espérant obtenir la libération de la Moldavie, a en effet commis l'erreur de s'allier à Pierre le Grand contre la Sublime Porte.

Le but déclaré des tsars et des armées russes était de libérer ces territoires de la domination ottomane, tendance visible au cours de la guerre russoturque (1735-1739) mais révélée notamment par les projets de Catherine II, qui avait mené des guerres contre les Turcs et forcé les boyards moldaves à formuler une demande exigeant entre autres que le chef de l'administration militaire de la Moldavie soit un général russe (Berg, 1918: 64).

Afin de justifier sa politique des siècles passés, la Russie a intensément promu le «mythe de sa mission divine de libération et de civilisation des nations $»^{84}$. Sous prétexte de protéger les minorités chrétiennes, la Russie s'octroie une influence prédominante. Cette conception a été constamment utilisée par l'impérialisme russe pour justifier ses revendications territoriales ou autres: elle a été ainsi utilisée par la diplomatie russe dans sa politique balkanique, y compris dans le cas de la Principauté de Moldavie. Les intérêts de la Russie visaient le contrôle et le libre accès des détroits du Bosphore et des Dardanelles, plus importants centres commerciaux de l'époque et le commerce sur la mer Noire vers la mer Méditerranée et inversement. La

81 http://www.limbaromana.md/index.php?go=articole\&n=573

82 Les principautés roumaines, en général, et la Bessarabie, en particulier, ont toujours été considérées par le tsar, comme une étape intermédiaire sur le chemin vers Constantinople, une porte vers les Balkans, clé stratégique de l'extension de l'influence russe sur les peuples slaves orthodoxes du Sud.

83 L'État russe fut officiellement appelé Empire russe, de 1721 sous le règne de Pierre le Grand jusqu'à la déposition de Nicolas II, le dernier tsar, au début de la Révolution de 1917.

84 Il s'agit d'un ensemble d'idées, de théories et de préjugés concernant le rôle de la Russie dans le monde et ses relations avec les voisins; celle-ci est montrée comme sauveur et «civilisateur» des nations. 
lutte menée par le tsar russe Pierre le Grand ou la tsarine Catherine II pour accéder au débouché maritime du sud, est un axe important de "[...] la géopolitique russe et l'orthodoxie susceptible d'être menacée par l'islam dans les Balkans [...]» (Serebrian, 2006: 9).

L'histoire de ce territoire est difficilement compréhensible si l'on ne garde présente à l'esprit une idée précise de la géographie de la région: cette bande de terre comprise entre le Prut et le Dniestr a constitué dès ses origines, un enjeu militaire et stratégique prépondérant pour la Russie. Le rêve ambitieux des tsars russes: posséder un débouché maritime permettant l'accès aux détroits des Dardanelles, du Bosphore et de Constantinople, place la Principauté de Moldavie au premier plan de l'expansionnisme russe. Dans sa progression vers les embouchures du Danube, l'Empire russe obtient de

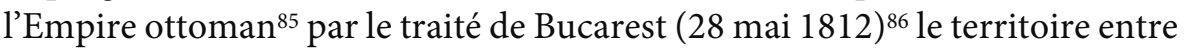
Prut et Dniestr de la Principauté de Moldavie dont le statut sera réformé; elle sera transformée en province russe appelée goubernia de Bessarabie ${ }^{87}$. Le droit de domination de la Russie sur un territoire habité depuis un millénaire au moins par des Roumains aux côtés d'un petit nombre d'autres nationalités établies durant la période médiévale et l'intégration de la Bessarabie roumanophone dans l'espace culturel slave de la Russie tsariste sont tous deux injustifiés.

\section{Bessarabie : annexion et recomposition}

Au début du $\mathrm{XIX}^{\mathrm{e}}$ siècle, le problème de la Bessarabie est devenu une constante de la diplomatie européenne, à partir du moment où les

85 L'affaiblissement de l'Empire ottoman conduisit la Principauté de Moldavie à être fréquemment occupée et partiellement démembrée par la Russie et l'Autriche. En 1775, l'Empire ottoman récompense l'Autriche de sa neutralité dans ce conflit en lui cédant la partie nord de la Moldavie, la Bucovine.

86 C'est un traité international signé à Bucarest entre l'Empire ottoman et l'Empire Russe, mettant fin à la guerre russo-turque. Par ce traité, les deux parties ont frauduleusement transgressé l'intégrité de la Principauté de Moldavie.

87 Le nom de Bessarabie a désigné successivement: la Principauté de Valachie, au début du XIV ${ }^{e}$ siècle, du nom de sa dynastie fondatrice, les Bessarab. Plus précisément, elle a été nommée Bessarabie parce que le souverain Bassarab Ier de Valachie, en avait chassé les Tatars en plusieurs campagnes entre 1328 et 1342, puis l'avait cédée en 1418, à la Principauté de Moldavie dont elle a fait partie jusqu'en 1812. Elle comprend la zone méridionale Boudjak, qui a fait partie de la Principauté de Moldavie (1408-1484) puis a été cédée aux Ottomans (1538) et ultérieurement incorporée par le traité de Bucarest (1812) à la nouvelle goubernia de Bessarabie. C'est une région multiethnique située sur les bords de la mer Noire entre la confluence du Prut et l'embouchure du Dniestr au sud de la Moldova. Elle fait aujourd'hui partie de l'oblast d'Odessa, en Ukraine. 
Roumains, les Turcs, les Russes, contestèrent leurs droits sur la région située entre Prut et Dniestr. À la base des revendications territoriales, se trouvait le plus souvent le problème de l'identité ethno-nationale de la population majoritaire de Bessarabie (King, 2005: 12). L’identité du plus grand groupe ethnique de la région a constitué un sujet de discussions à connotation plus politique que scientifique (King, 2005: 24). La question qui se posait et se pose est la suivante: que les résidents de cette région, les Roumains aient été longtemps séparés de leur patrie et inclus dans le territoire russe, les fait-il devenir plus Slaves que Latins?

L'auteur russe L.S. Berg, intéressé par la question de la romanité des Roumains bessarabiens, a décrit des moments de l'histoire de ce territoire et des traits ethnographiques des Moldaves (Berg, 1923: 58) en interrogeant l'origine des habitants de l'espace danubien depuis les temps anciens. La romanité des Bessarabiens, de leur communauté avec les Roumains des Principautés roumaines révèle un trait fondamental de leur identité ethnique. L'historien et publiciste russe Pavel Petrovitch Svinin ${ }^{88}$ considère ce trait comme inhérent aux autochtones. L'auteur affirme que la Bessarabie a été arrachée à la Principauté de Moldavie, que son histoire est étroitement liée à l'histoire de cette dernière, que sa population a le même passé que l'ensemble du peuple roumain. Les autochtones, continue P.P. Svinin, sont des «[...] Moldaves ou Valaques [...] descendants des colons romains. Ils parlent la langue moldave qui est d'origine latine [...]»(Svinine, 1867:220). Nous retrouvons des idées similaires dans les Mémoires de l'ex-gouverneur de Bessarabie Filip Vighel, témoignant qu'il a eu l'occasion d'étudier l'âme des Moldaves "[...] ces romani, comme ils se désignent eux-mêmes, descendant des colons romains et des Daco-Gètes [...] dans la langue desquels prédomine l'élément latin" (Vigel, 1865: 98). La première moitié du XIX ${ }^{e}$ siècle confirme l'importance de la langue des autochtones comme élément identitaire.

L'officier d'État-major de Russie A. I.Zasciuk a apporté dans ce domaine une contribution notable avec un ouvrage qualifié de premier travail scientifique sur la Bessarabie. Il affirme en conclusion que «les Bessarabiens comme les Roumains des Principautés sont d'origine occidentale, qu'ils descendent des Romains [...], ont subi des influences différentes mais ont gardé le caractère de leurs ancêtres» (Zasciuk, 1862: 151). L'ethnographe

88 Qui se fondait sur les informations reçues de la part des locaux, ce qui atteste d'ailleurs une auto-conscience de ce fait, confirmant la conclusion sur la formation débutante de certains éléments identitaires parmi eux. 
A. I.Zasciuk s'intéresse à d'autres aspects: il constate des points communs entre les autochtones de Bessarabie et ceux des Principautés roumaines (se référant à l'identité entre les Roumains des deux rives du Prut), une communauté d'évolution des Bessarabiens et de leurs frères des Principautés roumaines au $\mathrm{XIX}^{\mathrm{e}}$ siècle (Zasciuk, 1862: 450): il s'agit du même peuple mais des destins historiques différents ont fait apparaître chez les Roumains bessarabiens des éléments distincts, qui contribueront ultérieurement à la formation d'une nouvelle nation en Bessarabie, avec des particularités relatives aux habitants de la Roumanie aussi. L'auteur relie aussi l'histoire de la Bessarabie à celle des Principautés roumaines du seul fait qu'il communique en annexe de son œuvre, une liste complète des princes des Principautés (Zasciuk, 1862: 253-260). En outre, il inclut la Bessarabie dans l'espace de l'histoire roumaine ${ }^{89}$.

P. Batiuşkov a rédigé un autre travail représentatif de cette époque, donnant d'importantes informations sur l'image que les Russes se faisaient de la Bessarabie et des Roumains vus comme des demi-Slaves ou des étrangers. À un moment, il reconnaît que la population rurale de ce temps ne connaît pas le russe. Les Roumains sont les plus nombreux en Bessarabie et évidemment leurs regards sont tournés vers leurs compatriotes du Royaume de Roumanie (Batuchkov, 1892: 174). En raison de l'implication politique de l'ouvrage, la citation susmentionnée confirme que l'origine ethnique des Roumains est vue par les auteurs russes comme un élément primordial de la notion d'identité. Dans l'œuvre de P. Krouchevan, souvent accusé de visions anti-roumaines et d'opinions politiques radicales, l'origine romaine des Bessarabiens est clairement affirmée, prouvant la portée de cette composante du portrait des Bessarabiens: «Les Moldaves ou Roumains constituent la majorité de la population de la Bessarabie. La parenté étroite de leur langue avec les autres langues d'origine latine [...] et leur nom de Roumains ne laisse subsister aucun doute sur cette nation [...]» (Krouchevan, 1903: 323).

L. A. Casso a particulièrement insisté sur un problème, lié aux opinions de certains slavophiles ou hommes d'État russes: il s'agit de l'opportunité de restituer la Bessarabie à la Roumanie ou de l'inutilité de cette acquisition territoriale pour l'Empire russe. Son ouvrage Russie sur le Danube se réfère aux opinions du principal idéologue du slavophilisme de cette période, N.I. Danilevski Exposées dans Russie et Europe paru en 1871, elles s'expriment clairement en faveur de la rétrocession de la Bessarabie

89 Nous ne devons pas oublier que son ouvrage a été écrit après l'unification des principautés. 
à la Roumanie (Danilevski, 2002: 27). L'auteur cite aussi la conclusion du général A. B. Kouropatkin suite aux guerres balkaniques: la Russie a atteint ses frontières naturelles en 1792, le traité de Paix de Iași ${ }^{90}$ leur a assuré une «bande de terre» (Casso, 1913: 229) comme il nomme le territoire entre Prut et Dniestr.

Les premières années après l'annexion ${ }^{91}$, la Bessarabie conserva un statut favorable. Une large autonomie (Bratianu, 1995: 23-30) lui a été accordée et des traditions moldaves - institutions ${ }^{92}$, division administrative et usage de la langue roumaine - ont été respectées. Ce statut changea radicalement le 29 février 1828, conformément au Règlement du prince Mikhail Vorontsov ${ }^{93}$. Dans la Bessarabie rattachée au Gouvernement Général de la Nouvelle Russie, une politique cruelle de dénationalisation et russification a été mise en place. Des fonctionnaires russes sont chargés de l'intégration de la province à l'intérieur de la Russie (Nouzille, 2004: 121). La langue russe devient la langue de la justice, de l'enseignement, du clergé, de l'administration même si les actes administratifs restent publiés en roumain. Dès 1833, la langue roumaine commence d'être progressivement exclue de l'administration. En 1867, elle est bannie de l'enseignement public et des Églises ${ }^{94}$ au profit du russe (Boldur, 2000: 203). En 1878, la langue roumaine est interdite et remplacée par le russe ${ }^{95}$. Parallèlement, le russe a peu à peu évincé le roumain en tant que langue officielle de l'administration, de la science, de la technique et de la culture. Les valeurs spirituelles nationales sont négligées, la conception fausse concernant la différence ethnolinguistique entre Moldaves de Bessarabie et ceux de la rive droite du Prut est inculquée.

Les autorités russes encouragèrent l'émigration, déportèrent des Bessarabiens considérés comme de même groupe ethnique que les Roumains dans d'autres provinces de l'Empire (notamment au Kouban, au Kazakhstan, en Sibérie). En revanche d'autres groupes ethniques, notamment les Russes et les Ukrainiens, étaient invités à s'installer dans la région. Le recensement de 1817 montrait la Bessarabie comme peuplée à $86 \%$ de Roumains, 6,5\%

90 Signé entre l'Empire russe et l'Empire ottoman.

91 Sous le règne d'Alexandre $1^{\text {er }}$.

92 Le Conseil supérieur de onze membres, pouvoir à la fois exécutif, législatif et judiciaire, à l'imitation du Divan de la Principauté de Moldavie.

93 Gouverneur général de la Nouvelle Russie et de la Bessarabie de 1828 à 1844.

94 L'Église commença à refuser de reconnaître les ecclésiastiques qui ne parlaient pas russe.

95 Après la Seconde Guerre mondiale, cette théorie fera partie de l'idéologie officielle du parti communiste en Moldavie soviétique. 
d'Ukrainiens, $1,5 \%$ de Russes et $6 \%$ issus d'autres groupes ethniques. Quatre-vingts ans plus tard, en 1897, la répartition ethnique a sensiblement changé: $56 \%$ de Roumains mais 11,7\% d'Ukrainiens, 18,9\% de Russes et $13,4 \%$ de personnes issues d'autres groupes ethniques. En quatre-vingts ans, la population roumaine a donc chuté de $30 \%$. La capitale, Chişinău, une bourgade sur la rive sud du Bâc a été transformée par les Russes en ville moderne selon les critères du $\mathrm{XIX}^{\mathrm{e}}$ siècle, pourvue du chemin de fer vers Odessa. De nombreux immigrants viennent y travailler de toute la Russie, des commerçants arrivent de Pologne et de Galicie, des Arméniens ouvrent des ateliers et des banques, ainsi que des Ukrainiens, des Allemands et des Suisses ${ }^{96}$. Les paysans roumanophones locaux doivent nourrir tout ce monde selon un modèle dans lequel les avait plongés l'annexion russe de 1812 jusqu'à son effondrement en 1917.

Le problème des relations entre autochtones et Russes (ou les ethnies colonisées plus tard par ces derniers) a des aspects très importants, surtout si on envisage la compréhension de la différenciation dans le cadre de l'identité97. Théoriquement, certains éléments déterminent l'identité d'un peuple dans la perspective de sa transformation en identité nationale. Dans toute construction identitaire, une combinaison de plusieurs facteurs contribuant à sa définition est nécessaire. L'historien roumain A. Pippidi a élaboré une classification très réussie des facteurs identitaires fondamentaux, à savoir: le nom national propre, la langue nationale, la communauté de religion, l'apparition d'une historiographie propre, l'unité politique (implicitement l'existence d'un État national [ethnique] propre) et une identité culturelle bien définie (Pippidi, 1996: 59). Évidemment les trois derniers facteurs ne peuvent être invoqués dans le cas de la Bessarabie à cette époque. L'identification par des auteurs de ces facteurs ne signifie pas que le peuple en ait conscience et qu'il y soit sensible. Concernant le nom des Bessarabiens, nous voudrions faire remarquer que les auteurs utilisent la désignation de "Moldaves» au même titre que celle de "Roumains». En tout cas, il n'existait pas à l'époque entre ces deux ethnonymes, d'opposition bien définie.

L'ethnonyme «Moldave» nous renvoyait à l'identification territoriale avec la Principauté de Moldavie mais celle de "Roumain» n'avait probablement pas encore acquis pour les Bessarabiens, une connotation ethnique porteuse de connotations sociales (Sarov, Cusco, 2001: 31). Les facteurs empêchant

96 Par exemple, en 1928, seuls 600 travailleurs de l'industrie sur 14300 sont moldaves.

97 C'est-à-dire de l'attitude de la part des autochtones vis-à-vis des étrangers. 
l'existence du concept d'identité nationale - roumaine - chez les Roumains bessarabiens de l'époque, ont aussi rendu impossible l'implémentation durable de conscience d'appartenance à un espace identitaire défini, à savoir «russe». La conservation de l'identité traditionnelle dans la population autochtone a empêché que s'exerce l'influence de l'idée nationale russe, l'implémentation de l'identité roumaine restant hors des projets nationaux de ces deux espaces. Potentiellement intéressés, les deux côtés se heurtaient à des pièges: la Russie, à la réalité «ethnique roumaine» majoritaire de la province et la Roumanie, à l'absence de "conscience roumaine» dans le cadre de cette ethnie (Șarov, Cusco, $2001: 34$ ).

Cependant, le facteur principal de « différenciation entre les autochtones et les autres [...] est la langue nationale», fait marqué par la persistance des revendications à ce sujet pendant toute la période de la domination russe. Le peuple roumain de Bessarabie vit complètement isolé de la population russe (Batuchkov, 1892: 175) et «dans l'avenir, l'unité du peuple roumain, se fera par voies paisibles ou par la guerre, c'est inévitable» (Kouropatkin, 1910: 33). Les rapports unissant à cette époque Russie et Roumanie étaient extrêmement ambigus mais dès 1878 , les relations se dégradèrent complètement. Lorsque la Roumanie fut érigée en royaume héréditaire en 1881, elle revendiqua la Bessarabie ${ }^{98}$ avec son importante population roumanophone. Mais cette dernière reste jusqu'en 1917, province de l'Empire russe. Sans représentation dans le processus législatif ou exécutif, elle sera rattachée à la Roumanie de 1918 à 1940 et de 1941 à 1944.

\section{Constatation de la romanité et identités ethniques des autochtones}

La Première Guerre mondiale (1914-1918) a amené de profonds changements géopolitiques, lesquels ont profondément modifié le cours du $\mathrm{xx}^{\mathrm{e}}$ siècle, causé l'effondrement ou la fragmentation des empires austrohongrois, ottoman et russe. La révolution russe de février 1917 et le droit des nations à s'autodéterminer, encouragent diverses nations de l'Empire russe à recouvrer leur souveraineté. Le concept lancé par V.I. Lénine ${ }^{99}$ sur

98 La Roumanie hésita longtemps avant de prendre part au premier conflit mondial: en 1915, l'Allemagne lui proposa une alliance en échange d'une promesse de retour de la Bessarabie.

99 Les facteurs raciaux et linguistiques seraient les premiers déterminants de la nationalité, les facteurs culturels et religieux n'ayant qu'une importance secondaire mais bien réelle. Confrontés à un territoire où les frontières nationales existantes étaient souvent mal définies ou inexistantes et ne correspondaient pas à des divisions territoriales impériales en vigueur, Lénine se fixa la tâche de dessiner des frontières nationales et territoriales 
la question du droit des nations à disposer d'elles-mêmes "se rapporte entièrement et exclusivement au domaine du droit à la séparation politique, à la constitution d'un État national indépendant» (Lénine, 1968: 160). L'insistance de Lénine sur le droit à la séparation ne signifie nullement qu'il est favorable au séparatisme et à la division à l'infini des États selon des lignes de fracture nationales. Au contraire, il espère grâce à la libre disposition des peuples sur leur propre destin, faciliter le maintien des États multinationaux. Lénine affirmait aussi qu'il y a «[...] deux nations dans chaque nation moderne [...], deux cultures nationales au sein de chaque culture nationale $[\ldots]$ » (Lénine, 1968: 158). Selon cet angle de vue, dans la vision de l'idéologie soviétique, la culture et la langue russes avaient droit à un statut privilégié. À cet égard, les emprunts du vocabulaire russe et les éléments de la culture russe, imposés d'une façon plus ou moins voilée aux autres peuples soviétiques, se présentaient comme un phénomène normal.

En 1917, profitant des bouleversements qui secouaient une Russie en pleine révolution bolchevique un mouvement d'émancipation se développe et après le déclenchement de la Première Guerre mondiale, - les revendications quant à l'autonomie de la région ne cessèrent pas pour autant -. Le 9 avril 1917 se crée le Parti national ${ }^{100}$ représentant les roumanophones majoritaires dans le pays et réclamant une large autonomie administrative, judiciaire, scolaire (Ruzé, 1999: 16). Le 21 novembre 1917, l'Assemblée nationale (Sfatul Țării) proclame l'autonomie de la Bessarabie. Le 2 décembre 1917, elle se déclare République démocratique autonome de Moldavie dans les frontières de la goubernia de Bessarabie, toujours dans un cadre de République fédérative démocratique russe. Sur les 156 députés, 105 se déclarent roumanophones, 15 Ukrainiens, 14 Juifs, 7 Russes, 2 germanophones, 2 Bulgares, 8 Gök-Oguz, 1 Polonais, 1 Arménien, 1 Grec. Lors de sa première séance solennelle, l'Assemblée nationale proclame l'égalité hommes-femmes, la laïcisation de la société, l'abolition de tous les privilèges aristocratiques, la nécessité d'une réforme agraire et l'égalité des langues (auparavant, seul le russe avait un statut officiel) (Clark, 1927:101). Le roumain est adopté comme langue officielle et d'enseignement.

à partir de presque rien: ainsi, des ethnologues et des linguistes furent envoyés dans diverses parties de l'ancien empire afin de «découvrir» des nations.

100 Le parti était présidé par Stroescu V., entouré de Gore P., Herța V., Halippa P. et Ghibu O., et publié dans l'hebdomadaire Cuvânt moldovenesc (Parole moldave).

$101 \mathrm{http}: / /$ depts.washington.edu/cartah/text_archive/clark/bc_18.shtml 
Pour faire face aux attaques des troupes bolcheviques et aux menaces annexionnistes de l'Ukraine, l'Assemblée nationale fait d'abord appel à l'armée roumaine qui intervient en Bessarabie le 15 décembre 1917 avec des troupes franco-roumaines commandées par le Français Berthelot. Puis le 6 janvier 1918, la nouvelle république déclara son indépendance complète face à l'Empire russe sous le nom de République démocratique moldave de Bessarabie. Toutefois, cette première République moldave aura une existence brève: le 27 mars 1918, l'Assemblée nationale, effrayée par les proclamations révolutionnaires et les actions militaires des bolchéviks (Chirițescu, 1988: 420) vote la réunification de la Bessarabie ${ }^{102}$ avec les Principautés unies de Roumanie (ou Vieux Royaume) (Harea, 1995: 275) créant ainsi la région historique de Grande Roumanie. C'est la plus grande extension territoriale qu'ait jamais connue le pays. Dans son livre La Moldova entre la Roumanie et la Russie: de Pierre le Grand à Boris Eltsine, Alain Ruzé mentionnait que "le rattachement de la Bessarabie à la Roumanie se justifiait compte tenu desaspirations générales du peuple bessarabien, le caractère moldave de cette région ainsi qu'en fonction d'arguments géographiques, ethniques, économiques, historiques» (Ruzé, 1997: 16). Ce rattachement est considéré par les Roumains comme l'achèvement d'un processus d'éveil social et national des roumanophones en tant que groupe ethnique. L'intégration de la Bessarabie à la Roumanie avait été entérinée par les Alliés ${ }^{103}$ au traité de Paris (28 oct. 1920) mais elle n'a pas été reconnue par l'URSS, non-signataire du traité (Ledermann, 1948: 571).

Les relations entre la Roumanie et l'Union soviétique - interrompues à l'initiative du gouvernement soviétique le 13 janvier 1918 - ont été particulièrement tendues, suite à l'Acte d'union de la Bessarabie avec la Roumanie dont le gouvernement soviétique niait la légitimité, exigeant en 1940, la restitution du territoire compris entre Prut et Dniestr ${ }^{104}$. Dans la période d'après la Grande Union, la société roumaine connut simultanément avec l'état d'euphorie nationale, un processus complexe et contradictoire d'autodéfinition sur le plan interne et externe, absolument naturel et inévitable, suite à l'extension substantielle du territoire de l'État roumain et à

102 Du 27 mars 1918 au 2 août 1940.

103 La Grande-Bretagne, la France, le Japon et l'Italie.

104 Comme on sait, les négociations préliminaires à l'établissement des relations diplomatiques entre les deux pays ont commencé en mai 1934 et ont été suivies d'échanges de lettres et notes diplomatiques par lesquelles la Roumanie et l'URSS se garantissaient le respect réciproque de la souveraineté et non-ingérence dans les affaires intérieures des pays voisins. 
l'intégration d'un nombre considérable de populations hétérogènes du point de vue ethnoculturel et linguistique.

L'exaltation nationaliste de la période de la Grande Roumanie n'a pourtant pas entraîné de politique agressive de discrimination ou d'assimilation culturelle des populations non roumaines en effet, fortement mélangées: aux côtés des Roumains, on trouvait des Russes, des Ukrainiens, des Ruthènes, des Biélorusses, des Arméniens et des Suisses (Castellan, 2004: 177). Prenant pour point de départ des publications scientifiques de l'Académie de Leningrad et tout particulièrement des travaux de Lev Semenovitch Berg (Berg, 1923: 61), le savant soviétique le plus connu étudiant les aspects ethnographiques et démographiques de la Bessarabie nous prouve la présence prédominante des Roumains sur le territoire compris entre Prut et Dniestr. Ceux-ci représentaient $54 \%$ de l'ensemble de la population, suivis par les Ukrainiens (20,31\%), les Juifs (7,25\%), les Bulgares (5,58\%), les Russes (5,12\%). La Bessarabie est nommée «la Moldavie située sur la rive gauche du Prut» (Skalkovskii, 1838:32). C’est là que se trouve la vérité tout entière: pas seulement historique mais aussi ethnographique. La région entre Dniestr et Prut est une terre purement moldave.

Les intellectuels bessarabiens les plus importants: Z. Rali-Arbore, V.Crăsescu, I. Halippa, C. Stere ont considéré que la reconnaissance de l'origine ethnique commune à la majorité de la population entre le Prut et le Dniestr et aux Roumains du Grand Royaume de Roumanie reposait sur une argumentation scientifique. Parallèlement à l'essor du mouvement national englobant la Bessarabie suite à la révolution de février 1917, l'élite des intellectuels a insisté sur la nécessité de penser l'identité nationale roumaine.

Au congrès des professeurs moldaves (les 25-28 mai 1917), l'auteur du poème Limba noastră (Notre langue maternelle), le prêtre-poète moldave Mateevici Alexei incitait ainsi les professeurs «[...] vous avez assumé la tâche d'instruire le peuple, donc vous devez lui donner des idées véritables sinon tout l'enseignement est sans ordre» (Mateevici, 1993: 463). Il insistait sur la nécessité de dénommer correctement la langue et le peuple indigène de Bessarabie, déclarant $«[\ldots]$ nous sommes [...] fils de la vieille Moldavie mais nous faisons partie de la grande communauté roumaine. Nos frères de Bucovine, Transylvanie, Macédoine ne s'appellent pas d'après les lieux où ils habitent mais ils se nomment Roumains. Nous devons faire de même» (Mateevici, 1993: 463). Le poète incitait les professeurs bessarabiens à cultiver le sentiment de l'unité ethnique dans la population: «Nous devons savoir qui sont nos ancêtres, sinon nous sommes perdus. Nous devons savoir que nous sommes Roumains, descendants des Romains et frères des Français, Italiens, 
Espagnols, Portugais. Cela nous devons le dire à nos enfants et à tous ceux qui sont illettrés» (Mateevici, 1993: 464).

Un autre intellectuel moldave P. Gore, expliquait: «le peuple roumain habite dans plusieurs pays, ainsi nous avons des Roumains d'Ardeal ${ }^{105}$, de Bucovine, de Munténie, d'Olténie, Roumains de Moldavie et Roumains de Macédoine, en un mot, nous sommes tous Roumains!»(Gore, 1992: 52). Sur la rive droite du Prut, à Iassy, des intellectuels roumains ont créé en 1927 la Légion de l'Archange Michel, mouvement nationaliste faisant l'apologie de la race daco-romaine et souhaitant débarrasser la nation roumaine de ses éléments étrangers (Laignel-Lavastine, 2002: 108).

La création de l'État unitaire national en vertu de la Constitution de 1923 a été présentée comme l'idéal millénaire du peuple roumain, officiellement défini à l'époque par la continuité biologique du lien du sang, la continuité spatiotemporelle de la patrie ancestrale, spirituelle de la communauté culturelle-linguistique, historique et symbolique religieuse (chrétienne orthodoxe). Cette idéologie de l'État unitaire romain plaçait l'accent sur la romanité culturelle-historique de toutes les régions du pays et, implicitement sur l'affirmation et la promotion exclusive de l'esprit roumain en tout domaine de la vie sociale. Ainsi l'approche officielle reflète et soutient les efforts de consolidation de l'État roumain unifié de jure, mais hétérogène de facto, donc en construction, à savoir, les efforts d'affirmation d'une identité collective nationale moderne, fondée sur l'appartenance à la communauté ethnique des Roumains et la citoyenneté roumaine (Tofan, 2008:106). En d'autres termes, pour la promotion sur le mode officiel et centralisé de l'idée d'identité roumaine, les thèses suivantes étaient importantes: le caractère latin de la langue, de la culture et de la nation roumaines, l'unité et la continuité de l'histoire de la nation, la roumanité éternelle du territoire et durant la quatrième décennie $\mathrm{du} \mathrm{xx}^{\mathrm{e}}$ siècle, l'orthodoxie. Le discours identitaire bessarabien de l'entre-deux-guerres (1918-1939) n'est ni stable ni uniforme, il se calque sur un mouvement continu de profondes transformations sociales et politiques caractérisant la période postérieure à l'Union.

La Russie avait donc abusivement occupé le territoire de la Roumanie, sans aucune justification historique, linguistique ou démographique. Mais malgré les procédés artificiels des autorités russes, la romanité de la Bessarabie

105 Un des noms roumains de la Transylvanie toujours usité par les Roumains d'aujourd'hui. 106 http://www.limbaromana.md/index.php?go=articole\&n=573 
ne pourra jamais être cachée ou contestée par quiconque ni même séparée du «tronc à partir duquel elle a grandi» (Caraman, 2007: 33).

\section{Moldavisation, indigénisation, latinisation}

\section{La construction des nations en URSS était}

une tentative "venant d'en haut" sponsorisée par l'État, afin d'établir ou de rétablir une identité nationale. Première étape, des "frontières nationales" furent tracées afin que la "nation" puisse être perçue comme une entité au territoire délimité. Deuxième étape, la nationalité devint une catégorie de classification bureaucratique pour chaque individu: elle était indiquée sur le passeport de chaque citoyen soviétique et devint un élément essentiel de l'“identité officielle" de chacun. Troisième étape, une "langue nationale" officielle fut établie [...] et la campagne d'alphabétisation s'assurera que la majorité de la population locale puisse lire, écrire la langue et la considérer comme "sienne". Finalement, une nouvelle "culture nationale" et une "historiographie nationale" furent créées, comportant mythes et légendes (Wheatley, 2007: 165).

Pour expliquer la forte division de la population en fonction de l'appartenance ethno-nationale et au nom de la langue, il faut remonter à l'origine du dilemme. Un des épisodes fondateurs de la politique nationale et linguistique s'est produit à l'Est de la Bessarabie, à cette époque partie intégrante de la Roumanie ${ }^{107}$, sur la rive gauche du Dniestr où le 12 octobre 1924 les Soviétiques ont créé (Repida, 1983: 197) la République autonome socialiste soviétique de Moldavie (Șișcanu, 1992: 62), unité territoriale et administrative dans le cadre de la République socialiste soviétique d'Ukraine ${ }^{108}$, cette dernière faisait déjà partie de l'URSS (Ciocanu, 2004: 7). Cette entité incluait le territoire de la Transnistrie actuelle ${ }^{109}$ où de nombreux villages sont peuplés de Moldaves depuis le XVII ${ }^{\mathrm{e}}$ siècle. On y

107 du 27 mars 1918 à 2 août 1940.

108 Située entre Dniestr et Boug, elle incluait la région autonome de Transnistrie (qui appartient aujourd'hui à la République de Moldova) et des zones aujourd'hui partie constituante de l'Ukraine.

109 Ce territoire n'a appartenu ni à l'ancienne Principauté de Moldavie ni à l'ancienne Bessarabie. Jusqu'en 1944, c'était une région ukrainienne située en URSS, entre Dniestr et Boug méridional où vivaient des minorités roumanophones, où les Soviétiques instituèrent une RASSM, occupée par les Roumains alliés à l'Allemagne de juin 1941 à février 1944 sous le régime Antonescu qui en fit une Sibérie roumaine. La capitale officielle était la ville temporairement occupée de Chisinau, mais la capitale effective de 1924 à 1929 fut la ville ukrainienne de Balta, puis, à partir de 1929, Tiraspol. 
comptait en 1926, 572114 habitants (Berindei, Thédrel, $2003::^{110}$ ) dont 49,6\% d'Ukrainiens, 31,6 \% de Moldaves et 6,71\% de Russes (Stratievskiy, 1995: 29), ce qui montre que la décision de création de la RASSM par l'URSS n'était fondée que du point de vue idéologique et propagandiste (Cașu, 2000: 40). En 1927, pour la première fois au cours de la période soviétique, le linguiste M.V.Sergievski a formulé une théorie sur la langue "moldave», en tant que langue romane différente de la langue roumaine (Heitmann, 1998: 71). Cette théorie a été reprise par le linguiste transnistrien L.A.Madan, qui a essayé à partir de 1930, d'élaborer une nouvelle langue littéraire sur la base du parler moldave. Ainsi vont apparaitre dans cette république «une langue et une littérature nouvelle», première étape de rapprochement des langues «moldave» et «russe» au détriment du roumain, considéré comme un élément dangereux (Nouzille, 2004: 173) par le pouvoir soviétique. La République autonome socialiste soviétique de Moldavie a été un de ces «bantoustans soviétiques "111 selon Hélène Carrière d'Encausse où les autorités ont expérimenté des «novlangues» (Carrière d'Encausse, 1990: 43). Conséquemment, la République autonome socialiste soviétique de Moldavie est créatrice de la théorie de la langue moldave ou moldavisme.

À côté de la politique de moldavisation (Negură, 2009:112) a été mise en place celle d'indigénisation ${ }^{113}$. Si la première a contribué au développement de la langue nationale (il fallait alphabétiser les citoyens dans leur langue maternelle afin de les mobiliser politiquement), la deuxième a contribué à la promotion des petites nationalités pour des fonctions de cadres dans les administrations, les tribunaux, l'enseignement, les médias. Cette politique avantagea la langue des petites nationalités et consolida leurs identités nationales dans le but de les engager dans le processus révolutionnaire d'édification socialiste. De plus, Moscou admit directement que les Moldaves faisaient parti de la nation roumaine ${ }^{114}$.

$110 \mathrm{http}: / /$ www.politiqueinternationale.com/revue/read2.php?id_revue=14\&id=200\&search $=\&$ content $=$ texte

111 Territoire, où la population est forcée à se regrouper.

$112 \mathrm{http}: / /$ www.regard-est.com/home/breve_contenu.php?id=943\&PHPSESSID=014747a3f $45 \mathrm{~d} 7 \mathrm{~b} 30 \mathrm{e} 147 \mathrm{bf} 70 \mathrm{c} 65 \mathrm{a} 2 \mathrm{ae} 3$

113 La loi sur la moldavisation adoptée en juin 1926, se propose notamment de garantir "l'égalité plénière entre la langue moldave et les autres langues véhiculées en RASSM; l'utilisation de la langue moldave dans toutes les institutions d'État; la formation et la promotion des cadres d'origine moldave dans les organes du Parti et ceux administratifs».

114 Le premier recensement soviétique de 1926 a enregistré la population moldave du territoire de la RASSM sous la rubrique «Moldave, Roumains». 
Le premier recensement soviétique de 1926 a entrepris de classer tous les citoyens soviétiques selon leur nationalité (Wheatley, 2007: 163), il a enregistré la population moldave du territoire de la RASSM sous la rubrique «Moldaves, Roumains». Favorisant l'accès de la population locale à la scolarisation et à l'exercice du pouvoir, la moldavisation et l'indigénisation servent à légitimer la création de la République autonome socialiste soviétique moldave ainsi que l'instauration du régime bolchevique dans la région ${ }^{115}$.

La réforme linguistique initiée en 1932 qui officialise de fait la langue roumaine, est conçue pour favoriser l'ouverture de la politique soviétique, par la République autonome socialiste soviétique de Moldavie vers la Bessarabie, peut-être dans l'espoir d'encourager la dissidence de cette dernière. La politique linguistique de latinisation qui a eu lieu en RASSM, donna officiellement à la minorité roumaine de cette entité qui constituait $32 \%$ de sa population ${ }^{116}$, de nombreux droits comme par exemple: le droit de parler sa langue, de transmettre sa culture à ses enfants, d'ouvrir des écoles et de posséder ses propres organismes de presse. Les Roumains de la République autonome socialiste soviétique de Moldavie sont éduqués en roumain, écrivent en caractères latins.

Joseph Staline mentionnait à ce sujet que «la minorité n'est pas mécontente de l'absence d'une union nationale mais de l'absence du droit d'utiliser sa langue maternelle [...] donnez-lui la possibilité d'utiliser sa langue maternelle et le mécontentement disparaîtra de lui-même». Il insistait sur l'introduction de l'alphabet latin en RASSM dans l'intention «de rapprocher les peuples moldave et roumain".

L'union des deux régions: la RASSM et la Bessarabie, constituait un objectif permanent de la politique soviétique (Heitmann, 1998: 79).

Ces politiques d'indigénisation et de latinisation sont interrompues en 1938 tout aussi brusquement qu'elles ont été lancées (Negură, 2011: 57). Une vaste politique de dénationalisation de la population roumaine de la RASSM a été menée: des populations russophones et ukrainophones ont

115 Cette politique «libérale» de Lénine ne dura pas très longtemps et en 1928, Staline favorisa plutôt la russification de l'URSS en généralisant l'emploi du russe comme langue de travail et l'immigration des Russes, par exemple en 1928, sur 14300 travailleurs de l'industrie, seuls 600 sont moldaves, sans oublier les déportations massives en Sibérie (en 1937 les intellectuels roumains de la RASSM sont accusés par les Soviétiques d'espionnage et de sabotage et pratiquement tous sont évincés de leurs postes, réprimés et beaucoup d'entre eux exécutés).

116 La RASSM estimait environ 545500 habitants, les Ukrainiens constituant $46 \%$. 
été encouragées à s'établir dans la république, l'enseignement de la langue roumaine en tant que telle a été interdit dans les écoles. Les autorités soviétiques ont changé son nom même en "moldave», créé l'alphabet moldave écrit en caractères cyrilliques ${ }^{117}$, prétendant qu'il s'agit d'une langue distincte du roumain. Ce changement d'alphabet est officiellement motivé dans l'objectif de faciliter la communication avec les slavophones tandis que la langue russe, déclarée langue de communication interethnique devient pour les roumanophones la condition d'accès à un meilleur niveau d'éducation, d'ascension sociale et de pouvoir politique. La théorie sur la langue moldave était destinée à être une tête de pont pour la reconquête de la Bessarabie, devenue un outil pour la formation artificielle d'une nation. Cette théorie affiche l'idée de l'existence d'un "peuple moldave» proche mais différent de la nation roumaine. Il reste à mettre au point les coordonnées géographiques et symboliques de cette nouvelle entité: la langue, l'histoire, le patrimoine culturel. Les frontières de la "nationalité moldave» feront dès lors l'objet de débats prolongés jusqu'à la fin des années 1930 dans le cadre du Comité scientifique moldave, filiale locale de l'Académie des sciences ukrainiennes, des forums administratifs en fonction des intérêts politiques poursuivis par les différents agents et groupes impliqués dans l'«édification nationale» sur ce territoire. Les élites formées comme les politiques appliquées en RASSM joueront dès lors un rôle directeur dans la nouvelle République socialiste soviétique de Moldova de 1940 à 1991.

\section{République socialiste soviétique de Moldavie}

Le pacte de non-agression entre l'Union soviétique et l'Allemagne nazie, dit Pacte Ribbentrop-Molotov, signé le 23 août 1939, délimitait les sphères d'influence des deux puissances respectives et il supposait la destruction des États voisins (Courtois, Panne, 2005: 3). En ce qui concerne le SudEst de l'Europe (Gorodetsky, 1997: 4), les Soviets attirèrent l'attention sur leurs intérêts en Bessarabie ${ }^{118}$. Les Allemands déclarèrent qu'ils se désintéressaient complètement au plan politique de ces régions. Ainsi les deux partenaires convinrent d'attribuer la Bessarabie à l'URSS en secret, c'est-à-dire sans aucune consultation des intéressés (Durandin, 2003:391119). Par conséquent, l'Union soviétique n'aurait plus à engager de pourparlers

117 Cela devient la seule manière officielle d'écrire en RASSM.

118 Pacte germano-soviétique de non-agression Ribbentrop-Molotov. 23 août 1939, voir http://fr.wikisource.org/wiki/Pacte_Molotov-Ribbentrop

$119 \mathrm{http} / / / \mathrm{www}$.diploweb.com/forum/gdurandin2.pdf 
diplomatiques avec la partie roumaine, «ni de région tremplin pour exporter son idéologie» (Negură, 2011: 58). Comme conséquence directe du Pacte Ribbentrop-Molotov, le 28 juin 1940, la Russie occupe (Văratec, 2000 : 229) la Bessarabie ${ }^{120}$ qui faisait alors partie de la Roumanie et l'annexe à la Transnistrie (partie de la RASSM), toutes deux formant ensemble le 2 août 1940 (Tudor, 2004: 120) la RSSM121, érigée en République unionale à égalité avec la RSFS de Russie, la RSSF de Transcaucasie, la RSS d'Ukraine et la RSS de Biélorussie ${ }^{122}$.

On a pris à Moscou en 1940 la décision de constituer la République socialiste soviétique de Moldavie sans prendre en considération les intérêts de la population autochtone et en transgressant les législations internationales de même que la législation existante en Bessarabie. L'annexion par l'URSS du territoire entre Prut et Dniestr a eu des conséquences tragiques pour la population locale (Țăranu, 2010:123) qui a souffert de déportations (entre juillet 1940 et décembre 1953, 332500 personnes ont été déportées à partir de ce territoire) (Bugai, 2004: 363), de persécutions ${ }^{124}$, de famine et a été privée de ses valeurs ancestrales. Cet événement a arrêté l'évolution naturelle de l'histoire des territoires roumains annexés par les Soviétiques, inclus de force dans la composition de la RSSM.

La RSSM avait une population de 2538400 habitants, répartie ainsi: 2068987 habitants dans les districts de Bessarabie et 469413 habitants dans ceux de la RASSM. Selon les données démographiques du Rapport sur l'établissement de la frontière entre la RSS Ukrainienne et la RSSM ${ }^{125} \mathrm{du}$ 20 juin 1940, la population de la RSS moldave était constituée, du point de vue ethnique de - 1556863 Moldaves (61,34\%), 273020 Ukrainiens (10,76\%), 263551 Russes $(10,38 \%)$ et 444866 autres nationalités (17,52\%) (Șișcanu,

120 Sans les districts Akkerman, Ismail et une partie du district Hotin.

$121 \mathrm{La}$ Moldova fut ainsi privée d'environ $15000 \mathrm{~km}^{2}$ au profit de l'Ukraine, la région littorale Boudjak au sud et celle de Hotin au nord furent attribuées à la République socialiste soviétique d'Ukraine.

122 Qui ont constitué l'Union des républiques socialistes soviétiques le 22 déc. 1922 suite à la signature du Traité d'union (ratifié le 30 décembre 1922 par le premier Congrès des Soviets de l'URSS).

123 http://www.timpul.md/articol/-constituirea-rssm-a-avut-consecinte-tragice-marianataranu-13925.html

124 Les autorités soviétiques visaient plusieurs groupes socio-économiques en raison de leur situation économique, politique ou de leur lien avec l'ancien régime roumain.

125 Présentée par le secrétaire du Présidium du Soviet Suprême de l'URSS, A.Gorkin, au secrétaire du Comité Central du Parti Communiste de l'Union soviétique, G. M. Malenkov. 
Văratic, 1991: 34). Les étrangers: des Ukrainiens, des Russes, des Bulgares, des Gagaouzes, des Juifs, des Polonais, des Lituaniens, des Allemands, des Arméniens, des Tsiganes ${ }^{126}$ constituaient $38,66 \%$ de la population (Ghibu, 1996: 7). Dans l'ensemble de la Bessarabie, les Moldaves étant majoritaires, il n'existait aucune raison démographique de démembrement politicoadministratif de la Bessarabie ${ }^{127}$. Les autorités soviétiques n’ont pas pris en considération l'unité politico-administrative, économique et stratégique roumaine absolument justifiée historiquement et démographiquement de cette région. La création de la RSSM a eu pour conséquence d'abolir l'autonomie des Roumains qui y vivaient et en particulier leur droit de pratiquer leur langue. La nouvelle République officiellement créée "pour» les roumanophones d'URSS se révélera en pratique dirigée "contre» eux et c'est pourquoi les autochtones revendiqueront constamment et en masse, leur rattachement à la Roumanie.

En juin 1941, les troupes allemandes et roumaines attaquent l'URSS et occupent les territoires de Bessarabie et de Bucovine ainsi que la partie située entre Dniestr et Bug, que l'Allemagne et la Roumanie décident d'administrer sous le nom de Transnistrie avec Odessa pour capitale. Elles font de ce territoire une sorte de "Sibérie roumaine» où les armées allemandes et roumaines déportent les résistants. Beaucoup y mourront de faim, de froid, de maladie ou seront exécutés par les armées allemandes et roumaines. En dépit de l'existence en Transnistrie d'environ 500000 Roumains qui constituaient «l'avant-garde vers l'Est de la romanité et de la latinité» (Ghibu, 1996: 57), la majorité de la population restait constituée d'Ukrainiens et de Russes, ce qui explique probablement la décision de la Roumanie de ne pas procéder à une annexion en règle de cette région. Selon le Mémoire d'un groupe de militants du Parti Communiste de Russie, l'union des territoires des deux rives du Dniestr servirait d'ouverture stratégique de l'URSS vers les Balkans et l'Europe centrale, que l'Union soviétique pourrait utiliser comme simple tête de pont à des fins militaires et politiques. Le 24 août 1944, les troupes soviétiques reprennent à nouveau possession (Moraru, 2004:3) de la région

126 Ils ont été amenés par le régime tsariste, suite à l'occupation de la Bessarabie en 1812.

127 L'inclusion des districts Hotin, Akkerman et Ismail, qui faisaient partie de la Bessarabie à l'Ukraine, en 1940, a été motivée par le fait que sur leur territoire, la population ukrainienne prévalait par rapport à la Moldave, la composition ethnique de la population étant présentée par les autorités soviétiques comme suit: à Akkerman - $18 \%$ de Moldaves et $20 \%$ d'Ukrainiens -, à Hotin - 35\% de Moldaves et 41,6\% d'Ukrainiens et à Ismail - 31\% de Moldaves et 4,7\% d'Ukrainiens. D’après les données présentées, la population ukrainienne des districts bessarabiens incorporée à l'Ukraine est minoritaire par rapport à la Moldave. 
de Moldavie orientale (la Bessarabie) ${ }^{128}$, la fusionnent à la partie occidentale de la RASSM (la Transnistrie) ${ }^{129}$ et organisent à nouveau la RSSM ${ }^{130}$ dans ses frontières de 1940. Celle-ci devient alors la 15épublique de l'Union, qui réintégrera l'URSS jusqu'à sa dissolution en 1991.

\section{Réformes linguistiques}

À la suite du retour de la Bessarabie dans le giron soviétique en 1944, la propagande soviétique a maintenu «[...] les ressentiments contre les Roumains, ces "féodaux" qui voulaient soumettre le bon paysan moldave [...]» (Millot, 2009:131) et l'alphabet cyrillique a été imposé à la «langue reconnue officiellement comme "moldave" [...]», laquelle est «[...] identique au roumain littéraire, à une différence près: l'alphabet cyrillique » (Negură, $\left.2011::^{132}\right)$.

L'Union soviétique a repris son entreprise de déroumanisation et russification de la langue moldave commencées en Bessarabie en 1940 et 1941, afin de changer l'équilibre démographique en faveur des «occupants» russes. La différence entre le moldave et le roumain de Roumanie était cultivée systématiquement, notamment par un discours idéologique sur l'autonomie du moldave connu dans les années 1960 sous le nom de «théorie des deux langues»(Baggioni, 1994: 313). La politique linguistique des autorités ne favorisa pas la nouvelle langue au point de développer un enseignement supérieur en moldave et le russe devint, de facto, la langue du pouvoir, la langue de l'administration, de la justice, de l'église et de l'enseignement supérieur dans un pays majoritairement moldave. Les enfants fréquentaient

128 En 1947, la Roumanie reconnut officiellement l'intégration de la Bessarabie à l'Union Soviétique dans le traité de paix de Paris.

$129 \mathrm{La}$ Transnistrie s'urbanise et devient un bassin industriel de l'URSS tandis que la majeure partie de la Moldova, historiquement, géographiquement et culturellement liée à la Roumanie, demeure essentiellement rurale et agricole. Elle devient alors le centre économique de la RSSM avec $33 \%$ de la production industrielle et $56 \%$ de la production de produits de consommation, $90 \%$ de la production énergétique de la RSSM. La collectivisation ayant commencé dans cette zone dès les années 1920, le degré de soviétisation y est plus affirmé. Elle constitue également une pépinière pour l'élite de la République: de 1940 à 1989, tous les Premiers Secrétaires du Parti Communiste de la République proviennent de Transnistrie. La différenciation entre les rives occidentale et orientale de la RSSM tendra ainsi à se confirmer.

130 En même temps, la Bessarabie septentrionale, la zone en bordure de la mer Noire et la Bucovine septentrionale, territoire adossé aux Carpates du nord-est, furent attribuées à la République socialiste soviétique d'Ukraine.

$131 \mathrm{http} / /$ www.liberation.fr/monde/0101562283-chisinau-sous-emprise-roumaine

$132 \mathrm{http}: / /$ www.grotius.fr/la-transnistrie-les-origines-dun-conflit-gele/ 
sur une base volontaire les écoles moldaves, mais devaient apprendre le russe comme seconde langue ${ }^{133}$.

L'accession au pouvoir de Mikhail Gorbatchev en 1985, modifia progressivement les structures sociopolitiques en RSSM. La proclamation dela libération économique, culturelle et politique (Gorbatchev, 1987:23) connue sous le nom de perestroïka (restructuration) et de glasnost (transparence) ont bouleversé l'opinion publique dans toutes les formations nationales soviétiques. Le fameux Plénum du Parti Communiste de l'URSS d'avril 1985, a soulevé en Moldavie soviétique des problèmes d'historiographie du pays et de dégradation de la langue nationale parlée et écrite (Bruchis, 1999:17) suite à l'interdiction par les autorités soviétiques en 1944 d'utiliser l'alphabet latin. La libéralisation politique initiée par M. Gorbatchev donnera à la RSS de Moldavie l'occasion de mettre fin à la russification imposée à ce pays au cours de cette période. Cette politique se traduit en Moldavie par une revendication de reconnaissance de l'identité roumaine des autochtones qui avait notamment donné lieu aux déportations ${ }^{134}$ "punitives» de membres des familles d'opposants à la soviétisation de la Moldavie (Werth, 2009: 15). Ces déportations s'inscrivaient dans une politique de russification (Bugai, 2004: 365) initiée dans les années 1930, prolongée lors de la période des «purges» des années 1944-1955, particulièrement en Sibérie et dans les steppes du Kazakhstan ${ }^{135}$ (massivement en 1949), planifiant l'installation d'une forte population russe et ukrainienne dans la République (de nature à compenser par colonisation le déficit démographique).

La question d'une langue moldave distincte fournit l'arme principale de l'arsenal des "groupes informels» moldaves apparus en été 1988. Les Soviétiques ont longtemps considéré le critère linguistique comme fondamental pour l'identité nationale et aussi longtemps que la notion d'une langue moldave distincte a pu être soutenue, l'idée d'une nation moldave non-roumaine demeurera une proposition viable. Les écrivains, artistes, historiens et linguistes regroupés dans la principale organisation informelle moldave: le Front Populaire de Moldavie (à la base des mouvements d'opposition au pouvoir soviétique) demandaient le rejet de l'alphabet

133 Les parents avaient le droit d'obliger leurs enfants à recevoir leur instruction en langue russe.

134 Selon les données des recensements, de 1940 à 1950 la région a perdu un tiers de sa population, passant de 3200000 personnes selon le recensement roumain de 1938, à 2229000 selon le recensement soviétique de 1950.

135 Opérations de «nettoyage» et de «sécurisation» des zones frontalières de l'URSS. 
cyrillique en faveur de l'alphabet latin, la reconnaissance officielle de l'unité des langues roumaine et moldave et la déclaration du roumain comme langue d'État de la RSSM.

À la fin des années 1980, la question de la langue représentait un point sur lequel intellectuels et membres de l'élite politique moldave pouvaient se mettre d'accord. Impatients d'affirmer leur pouvoir par rapport au centre soviétique et par rapport au leadership du parti communiste local russifié, les acteurs politiques moldaves formèrent un front uni avec les intellectuels. Leur intérêt mutuel était clair:

[...] les écrivains, les artistes et les historiens moldaves espéraient susciter une renaissance de la culture nationale moldave (= roumaine), un but pour lequel beaucoup travaillaient depuis les années 1970, tandis que les élites politiques locales espéraient utiliser le mouvement national comme moyen d'obtenir de plus grandes concessions de la part de Moscou [...] (Ghervas, $2005: 136)$

et d'évincer le leadership brejnévien du Parti Communiste moldave.

Grosu Semion, premier-secrétaire du parti local, était en poste depuis 1980 et se distinguait par le fait qu'il était le dernier premier secrétaire républicain désigné sous Leonid Brejnev et le dernier à avoir été remplacé sous Mikhail Gorbatchev. Son style personnel et son manque de diplomatie lors des négociations avec le Front Populaire représentaient une continuelle source d'embarras pour M. Snegur, N. Țiu, A. Sangheli, membres du Bureau du Comité Central du Parti Communiste moldave ${ }^{137}$. En août 1989, lorsque la notion d'une distinction linguistique entre le moldave et le roumain était critiquée, S. Grosu affirmait encore que les deux langues étaient totalement distinctes et que l'alphabet latin était inapte à retranscrire la langue parlée. Comparés au premier secrétaire non réformateur, pratiquement tous les membres du Bureau du CC du PCM pouvaient se présenter comme des pragmatiques attachés au renouvellement de la culture nationale moldave au sein d'une Union Soviétique refaçonnée. La Constitution de 1978 modifiée par le Soviet Suprême de la RSSM malgré l'opposition des députés russophones, proclame le moldave comme langue officielle de l'État (1989), réintroduit l'alphabet latin (1989) et maintient également le russe comme «langue de communication inter - ethnique» (Bruchis, 1999: 18).

$136 \mathrm{http}: / /$ www.regard-est.com/home/breve_contenu.php?id=367

137 Le premier conseil (organe suprême) du Comité central du Parti communiste de la RSSM est le centre exécutif du PC RSSM qui définissait sa politique, sa ligne directrice. 
La lutte pour la reconnaissance officielle du moldave s'achève en août 1989. À la suite des républiques baltes et du Tadjikistan, le Soviet Suprême de Moldavie ${ }^{138}$ adopta le 31 août ${ }^{139}$ et le $1^{\text {er }}$ septembre 1989, trois nouvelles lois sur la langue: la loi relative au retour de la langue moldave à la graphie latine $^{140}$, la loi sur le statut de la langue officielle de la RSSM $^{141}$ et la loi sur le fonctionnement des langues sur le territoire de la RSSM, déclarant le moldave langue d'État de la république, «utilisée dans la vie politique, économique, sociale et culturelle et écrite dans l'alphabet latin ${ }^{142}$. Les lois satisfirent quasiment toutes les demandes du Front Populaire bien que la seule référence manifeste à l'unité des langues moldave et roumaine fût l'admission, du fait que les autorités tenaient compte de l'identité linguistique moldo-roumaine réellement existante.

Les nouvelles lois sur la langue représentaient la première étape dans la chute du Parti Communiste de Moldavie et le premier pas vers l'indépendance moldave hors de l'Union Soviétique. En adoptant les lois malgré l'opposition officielle du Parti Communiste, le Soviet Suprême moldave affirmait son pouvoir de véritable corps législatif, remettant ainsi en cause son précédent rôle de courroie de transmission des directives du parti communiste.

À ce moment, les divers mouvements autonomistes ou séparatistes apparaissent et expriment des revendications linguistiques, politiques et identitaires étroitement liées.

\section{Intérêts nationaux et ethniques}

Suite aux événements déclenchés après la Seconde Guerre mondiale, même a posteriori la "guerre froide»(1945-1991), ainsi que lors de la chute du communisme, une place particulière revient aux problèmes des minorités. En mai 1989 fut fondé un Front populaire, défenseur des valeurs de la nation, des intérêts nationaux et ethniques de la population autochtone. Ce mouvement inquiète les slavophones, qui forment en 1988 le mouvement

138 La plus haute institution exécutive en Moldavie, seule à pouvoir promulguer des amendements constitutionnels.

139 Cette journée du 31 août fut proclamée la Fête Limba noastră cea română (Notre langue maternelle) célébrée chaque année depuis 1989.

140 L. relative au retour de la langue moldave à la graphie latine, $n^{\circ} 3462-X I$ du 31 août 1989, Veștile RSSM, $\mathrm{n}^{\circ}$ 9/214, 1989.

141 L. sur le statut de la langue officielle de la RSSM, n 3464-XI du 31 août 1989, Veştile RSSM, $\mathrm{n}^{\circ}$ 9/216, 1989.

142 L. sur le fonctionnement des langues sur le territoire de la RSSM, n³465-XI du 01 sept. 1989, Veștile RSSM, n 9/217, 1989. 
Yedinstvo $^{143}$ (majoritaire en Transnistrie) tandis qu'en 1989 apparaît dans le sud le mouvement Gagauz Halkî (le peuple Gagaouze), qui représente une minorité de langue turque.

La chute du régime communiste roumain du 22 décembre 1989 a engendré un mouvement unioniste dans une partie de la population roumaine et moldave. Tous les changements qui ont commencé avec l'adoption en août et septembre 1989, des trois lois linguistiques - ce qui est perçu comme discriminatoire par les minorités - ainsi que la promotion du programme de réformes politiques, économiques, sociales du Premier ministre de la RSSM Mircea Druc (élu le 25 mai 1990) qui poursuivait la séparation de la RSSM de l'URSS ${ }^{144}$ puis la déclaration de la souveraineté de la RSSM ${ }^{145}$ vis-à-vis de l'Union soviétique en juin 1990, ne conviennent pas aux minorités.

Le "pont de fleurs» sur le Prut (nom donné aux événements de 16 juillet 1991 quand 240000 Moldaves ont traversé la frontière avec la Roumanie sans formalités) est un exemple symbolique de ces premières réactions enthousiastes. À l'occasion des élections présidentielles, législatives et sénatoriales qui se sont déroulées en Roumanie le 27 septembre 1992146, le Premier ministre de la RSSM Mircea Druc, a même présenté sa candidature en tant qu'indépendant puis il a présenté une plateforme unioniste dans l'idée d'une union des deux États telle celle qui avait été réalisée lors de l'élection de 1859 quand les principautés de Valachie et la moitié occidentale de la Principauté de Moldavie située entre les Carpates et le Prut, élurent toutes deux Alexandru Ioan Cuza (Matei, Nicolae, Negut, Radu, 2005: 21) comme prince commun. Mais le vainqueur des élections fut l'ancien communiste Ion Iliescu, qui avait fait ses études à Moscou et ne voulait gêner ni Gorbatchev ni Eltsine en posant la question de la RSS de Moldavie.

143 Signifie «unité» en russe.

144 Le Gouvernement dirigé par Druc M. (25 mai 1990 - 28 mai 1991) a institué les premières structures de l'Armée nationale, de la Police nationale, des Troupes de carabiniers et des services spéciaux d'information; il a introduit la langue roumaine comme langue d'enseignement dans des écoles, lycées et universités; il a fondé l'Académie de Sciences Économiques et l'Académie nationale de Police; il a contribué à l'ouverture des lycées bilingues roumain-français, roumain-espagnol, roumain-anglais, roumain-italien, roumain-allemand et à l'envoi pour poursuite d'études en Roumanie et dans d'autres pays de plus de 3000 élèves, étudiants, doctorants; il a éliminé le Parti communiste de la vie sociale.

145 Décision du Parlement de la RM relative à la Déclaration de la souveraineté de la RSSM, $n^{\circ}$ 148-XII, du 23 juin 1990, Veștile RSSM, nº 8/192, du 30 août 1990.

$146 \mathrm{http} / / /$ democratie.francophonie.org/rubrique.php3?id_rubrique $=633$ 
La fonction de Président de la RSSM ${ }^{147}$ a été instituée le 3 septembre 1990 et à cette date, Mircea Snegur a d'abord été choisi par le Soviet suprême avant d'être élu le 8 décembre 1991 Président de la République par des élections libres et démocratiques. Cette situation a provoqué une scission entre partisans de l'intégration à la Roumanie, menés par le Front populaire moldave de Mircea Druc et ceux d'une Moldova indépendante, rassemblés autour de Mircea Snegur.

Ces événements ont été suivis d'une nette aggravation des tensions interethniques entre les Moldaves et les minorités: Russes, Ukrainiens, Gagaouzes et des campagnes pour l'auto-détermination des minorités ont commencé. Alors que les roumanophones moldaves sollicitent la réunification avec la Roumanie, l'assemblée des soviets ruraux gagaouzes décide de proclamer unilatéralement une République de Gagaouzie reconnue par personne: cette entité se retrouve isolée. Contrairement à la Transnistrie qui a bénéficié jusqu'à l'effondrement de l'URSS de la majeure partie des investissements faits en RSS de Moldavie (Grünenwald, Rieu, 2008: 4), la Gagaouzie ne disposait d'aucun atout industriel ou stratégique: ni centrale hydroélectrique, ni usines d'armement, ni contrôle des voies de communication vers Odessa. Son seul atout économique était l'exportation de tabac. Aussi Stepan Topal, leader de la communauté gagaouze dutil à l'inverse de son homologue transnistrien Igor Smirnov renoncer à l'indépendance et accepter un statut juridique spécial ${ }^{148}$ au sein de la République de Moldova. Au même moment, la même politique était suivie par Igor Smirnov. Aussi le parti politique slave Yedinstvo qui fut créé pour demander une plus grande autonomie pour la Transnistrie, obtint l'organisation d'un référendum à la suite duquel les autorités locales annoncèrent, le 2 septembre 1990, la création de la République socialiste soviétique autonome de Transnistrie. Les revendications essentielles de ces deux entités étaient le rattachement à la Russie, ce que ni le Kremlin (Goanec, 2009:149) ni Chișinau ne veulent admettre.

Le 23 mai 1991, la RSSM devient la République de Moldova et le Soviet suprême de la RSSM devient le Parlement de la République de Moldova ${ }^{150}$.

147 Loi n ${ }^{\circ} 250$-XII relative à l'élection du Président de la RSSM, du 3 sept. 1990, Vestile.

148 L. sur le statut juridique spécial de la Gagaouzie, n³ 344-XIII du 23 déc. 1994, MO, nos 3-4/51, du 14 janv. 1995.

$149 \mathrm{http}: / /$ www.liberation.fr/monde/0101560393-qui-suis-je-il-parait-que-je-suistransnistrien

150 L. du Soviet suprême de la RSSM, nº 589-XII du 23 mai 1991, MP. 


\section{République de Moldova}

Le 27 août $1991^{151}$, le Parlement de la République de Moldova dans sa Déclaration d'indépendance d'une part déclare «la création d'un État souverain et indépendant, libre de décider du présent et du futur de la patrie sans aucune interférence étrangère», d'autre part pose que "la langue d'État est la langue roumaine ${ }^{152}$. C'est le seul document stipulant que la langue s'appelle roumaine. Après la proclamation de son indépendance qualifiée par les autorités «d'étape avant la réunification» (Naudet, 1991: 5) avec la Roumanie, un des plus importants événements d'envergure internationale a été représenté pour la République de Moldova par son adhésion le 2 mars 1992 à l'ONU, suite au vote à l'unanimité des pays-membres, fait qui a renforcé la reconnaissance de son indépendance.

L'aggravation de la situation survenue entre la fin de la perestroïka et la dislocation de l'URSS (26 décembre 1991) a commencé par une dégradation rapide de l'économie et des conditions sociales, à laquelle s'est ajoutée "une explosion des inégalités, des mouvements séparatistes et des conflits interethniques à la périphérie»(Chauvier, 2011:153). Les problèmes ethniques et territoriaux qui dominaient la vie politique moldave provoquèrent des violences entre éléments séparatistes, aidés de la $14^{\mathrm{e}}$ armée russe dans la région et nouvelles autorités moldaves dont «[...] le gouvernement ne contrôle pas la région entre le Dniestr et l'Ukraine ${ }^{154}$.

Après la brève guerre civile du Dniestr en 1992, la Moldova partagée en deux parties dont une est légale - la République de Moldova - et une se faisant nommer "République moldave du Dniestr» n'est pas reconnue par la communauté internationale ni même par la Russie, (Goanec, 2009:155) entrent dans un processus très difficile de transition (Dressler, 2005:156). L'accord de cessez-le-feu conclu le 21 juillet $1992^{157}$, prévoit le déploiement

151 Ce jour du 27 août fut proclamé jour de Fête nationale (qui est aussi la Ziua independenței/ Journée de l'Indépendance) célébré depuis 1991.

152 L. sur la Déclaration d'Indépendance de la RM, n 691-XII, du 27 août 1991, Moniteur du Parlement de la RM, nºs 11-12/103, du 30 déc. 1991.

$153 \mathrm{http} / /$ www.monde-diplomatique.fr/carnet/2011-08-23-URSS

$154 \mathrm{http} / / / \mathrm{www}$. state.gov/g/drl/rls/hrrpt/2004/41697.htm

155 http://www.liberation.fr/monde/0101560393-qui-suis-je-il-parait-que-je-suistransnistrien

156 http://www.cairn.info/revue-diogene-2005-2-page-34.htm

157 Un accord conclu en 1994 par la Russie et la Moldavie prévoit le retrait total de cette force. Une Commission conjointe de contrôle réunissant la Russie, la Moldova, l'Ukraine et l'OSCE est créée afin de favoriser le règlement politique du conflit et de superviser 
d'une force trilatérale de maintien de la paix (composée de troupes russes, moldaves, transnistriennes), le retour des réfugiés et la levée du blocus imposé par la Transnistrie pendant la guerre. La présence dans la région de l'ex-14 armée russe ${ }^{158}$ et l'afflux des mercenaires cosaques (Karlinsky, $1995: 159)$ du Don, du Kouban venus soutenir leurs «frères slaves» n'ont pas été de nature à calmer le jeu (Werth, $1993: 160$ ) malgré les propositions du président de la République d'accorder à la Transnistrie le statut de zone économique libre dotée d'une autonomie administrative. Ce compromis n'a pas suffi aux dirigeants de la Transnistrie qui exigèrent que le Parlement moldave accepte la réintégration de la Moldova dans la Russie (Werth, $\left.1994:{ }^{161}\right)$. Une année plus tard, la situation avait perdu de son acuité même si l'on reconnaissait de part et d'autre qu'aucun problème de fond n'était réglé162. Le gouvernement moldave demanda plusieurs fois l'intervention de l'ONU en vain et il concéda aux rebelles de Transnistrie la présence de Forces armées ${ }^{163}$ de la Fédération de Russie ${ }^{164}$ dans l'est de la République de Moldova jusqu'à ce que la région obtienne un statut politique spécial ${ }^{165}$.

Les stratèges occidentaux perçoivent qu'en Moldova ou en Transnistrie, il ne s'agit pas du sort de régions périphériques de l'Europe mais de lignes de séparation entre les deux grandes "plaques tectoniques géopolitiques» (Tudor, 2004: 123). Les stratèges russes considèrent à leur tour qu'évacuer la $14^{\mathrm{e}}$ armée de Transnistrie équivaudrait à une perte d'influence non seulement sur ce petit territoire mais dans les Balkans.

l'opération de maintien de la paix. L'OSCE qui prend une part de plus en plus active dans les négociations, semble rejeter aussi bien l'indépendance de la Transnistrie qu'une intégration pure et simple dans un État unitaire moldave.

http://www.operationspaix.net/136-historique-pkf.html

158 Grâce à son intervention, les Russes de Moldova avaient pu se soustraire au nouveau régime moldave.

159 http://www.liberation.fr/medias/0101132609-les-cosaques-les-cosaques-ces-vendeensde-la-revolution-russe

$160 \mathrm{http}: / /$ www.afebalk.org/edm/articles.php3?id_article=70

$161 \mathrm{http}: / /$ www.afebalk.org/edm/articles.php3?id_article=72

162 Les 1500 soldats russes qui étaient à l'époque venus à la rescousse des séparatistes sont restés sur place, officiellement en tant que «forces de maintien de la paix».

163 Renommée en 2005, le groupe opérationnel des forces russes en Moldova qui stationne sur place pour empêcher la Moldova de reprendre le contrôle de cette région.

164 La classe politique moldave a pris progressivement conscience que la stabilisation intérieure passait par la recherche de l'équilibre vis-à-vis la Russie.

165 En 1998 a été établie l'organisation administrative et territoriale de l'Unité administrative et territoriale de la rive gauche du Dniestr, par la L. relative à l'organisation administrative et territoriale de la RM, $\mathrm{n}^{\circ} 191-\mathrm{XIV}$, du 12 nov. 1998, MO, $\mathrm{n}^{\circ} 116$, du 30 déc. 1998. 
Les premières élections législatives libres de la République de Moldova de février 1994 sont remportées à $80 \%$ par les anti-unionistes, le bloc de gauche des agrariens et des socialistes (Munteanu, 2010: 13). À la suite de ces élections, le 6 mars 1994, dans le référendum consultatif sur le statut futur de la république (King, 1997:166) organisé sous le titre «Étude sociologique: En consultation avec le peuple»167 pour le maintien d'une «Moldova indépendante» dans ses frontières de 1990, c'est-à-dire incluant la Transnistrie, $95 \%$ des votants (participation de $75 \%)^{168}$ se sont prononcés en faveur d'un "État indépendant et unitaire ${ }^{169}$. La Roumanie déclare que le vote du Parlement moldave annule de manière irresponsable le droit de la nation roumaine à vivre dans l'intégrité de son espace culturel. Puis la position de la Roumanie devient plus modérée et le "Traité de fraternité et d'union politique» qui était en train d'être négocié devient le "Traité politique entre la Roumanie et la Moldova ${ }^{170}$.

L'une des premières tâches et des plus difficiles devant lesquelles s'est trouvé le Parlement moldave nouvellement élu a été d'élaborer et d'adopter une nouvelle Constitution (le 29 juillet 1994). Sur l'un des points les plus controversés: la langue officielle, le texte final opte pour le «moldave»171 comme langue de l'État (la déclaration d'indépendance se réfère à la langue «roumaine»). Bien que le moldave soit littéralement identique au roumain, l'option finale qui a perturbé le Front populaire symbolise le vœu du peuple moldave de renforcer son indépendance et son caractère distinctif vis-àvis de la Roumanie. Jusqu'aux élections, le Front populaire avait réussi à bloquer tout progrès à cet égard car le consensus sur un nouveau texte constitutionnel renforcerait l'indépendance de la nouvelle république, perspective allant à l'encontre des aspirations du Front populaire à un

$166 \mathrm{http} / / /$ balkanologie.revues.org/index195.html

167 Le texte de la question a été: «Êtes-vous d'accord pour que la République de Moldova se développe comme un État indépendant et unitaire, dans les frontières reconnues le jour de la proclamation de la souveraineté de la Moldavie (le 23 juin 1990), promeuve une politique de neutralité, entretienne des relations économiques mutuellement bénéfiques avec tous les pays du monde et garantisse à ses citoyens des droits égaux, en conformité avec les normes du droit international?»

$168 \mathrm{http}: / / \mathrm{www}$. a s se mbly.coe.int/ A S P / D oc/XrefView H T M L. asp? FileID $=6851 \&$ Language $=$ FR

169 La question se référait à l'indépendance et à l'intégrité territoriale, qui demeure une préoccupation particulière en raison du conflit transnistrien.

170 De décembre 1993 à 1995, les relations avec la Roumanie connaissent un net refroidissement.

171 Pourtant les élèves et les étudiants continuent à apprendre «la langue et la littérature roumaines» dans les écoles et les universités. 
rattachement à la Roumanie. Dans ce cadre constitutionnel, le parlement de Chişinău devait donc trouver une solution aux problèmes de la Transnistrie et de la Gagauz Yeri. La Constitution de la République de Moldova fixe le cadre d'un État unitaire et ne reconnaît pas les minorités.

Toutefois, l'article 111 intitulé Statuts spéciaux en matière d'autonomie qui donne une base juridique à la politique de décentralisation, prévoit en effet que «les régions situées sur la rive gauche du Dniestr ainsi que certaines autres régions dans le sud de la $R M$, puissent se voir accorder des formes spéciales d’autonomie conformément à des dispositions statutaires spéciales de la loi organique ${ }^{172}$.

Le territoire de Transnistrie reste jusqu'à présent sous le contrôle de facto des autorités autoproclamées de la république moldave du Dniestr. Dans les régions à population gagaouze, au contraire, le pouvoir est toujours resté aux mains des autorités moldaves légitimes, en dépit de la proclamation d'une république autonome. Le problème de la Transnistrie étant un problème surtout politique, il est nettement distinct de la question gagaouze qui est surtout une question ethnique.

À la fin des années 1990, la Moldova est devenue le pays le plus pauvre d'Europe, ayant de terribles problèmes de survie ${ }^{173}$. Elle est régulièrement agitée par des mouvements protestataires parce que le peuple moldave insatisfait de la corruption de ses dirigeants «démocrates» s'estime victime d'une dégradation brutale du niveau de vie. Ainsi sur fond de déception générale, les communistes «jouant sur la nostalgie de la période soviétique et sur un programme de rapprochement avec Moscou» (Parmentier, 2006: ${ }^{174}$ ) remportentles élections législatives du 21 février 2001. Le Parti des Communistes de la République de Moldova dont le leader, Vladimir Voronine est élu président le 4 avril 2001 par la nouvelle Assemblée obtient la majorité absolue au Parlement (71 sièges sur 101). Cet apparatchik (cadre supérieur du Parti communiste) «mi-russe mi-moldave» promet un rapprochement accéléré avec Moscou par le biais de l'intégration de la République de Moldova dans la CEI et s'engage à accorder au russe le statut de seconde langue officielle.

172 Constitution de la RM, du 29 juillet 1994, MO, n 1, du 12 août 1994.

173 Un quart de la population totale active émigrée à l'étranger a été jetée sur les routes de tous les trafics (drogues, prostitution, travail clandestin). Les revenus expédiés aux familles restées dans le pays, constituent deux cinquièmes du PIB de la Moldova.

174 http://www.diploweb.com/La-Moldavie-et-la-Transnistrie.html 
L'adoption d'une loi conférant au russe un statut particulier (juillet 2001) puis le renforcement de l'étude du russe à l'école prévu par le traité d'amitié russomoldave signé en novembre 2001, enfin la décision de rendre obligatoire l'enseignement du russe à l'école primaire à partir de janvier 2002 suscitent la vive colère des roumanophones qui descendent par milliers dans les rues à l'appel du Parti populaire chrétien-démocrate. L'appel à la grève générale lancé le 13 février 2002 par cette formation politique à la suite de l'annonce par le gouvernement de sa suspension pour un mois et de l'introduction d'un nouveau manuel d'histoire rappelant l'époque soviétique conduit le gouvernement à annuler toutes ses décisions et à destituer son ministre de l'Éducation le 26 février 2002 (Larousse: ${ }^{175}$ ).

Dans ces conditions de climat politique dégradé,l'Assemblée parlementaire du Conseil de l'Europe attendait des forces politiques moldaves qu'elles s'accordent sur un compromis concernant les contestations des réformes touchant le statut de la langue russe, l'enseignement de l'histoire et elle les invitait dans sa Résolution adoptée le 24 avril 2002, à prolonger «le moratoire sur les réformes concernant l'enseignement de la langue russe et son statut ainsi que la modification des programmes de l'enseignement de l'histoire» ${ }^{176}$. Un moratoire a été décidé. Les choses se sont ensuite calmées et le nouveau pouvoir s'est efforcé d'affirmer l'indépendance de la Moldova vis-à-vis de la Russie, recherchant l'appui des Occidentaux pour réduire la sécession de Transnistrie. Depuis que la Roumanie est entrée dans l'Union Européenne (2007), les Moldaves ont fait appel à la Roumanie, considérant que l'Europe commençait à Bucarest (Mongrenier, 2009: 3) puisque depuis le $1^{\text {er }}$ août 2003, les Moldaves bénéficient du droit de disposer de la citoyenneté roumaine, qui leur ouvre plus facilement les portes de l'Union européenne. Par conséquent, le président Voronine redouble d'hostilité envers la Roumanie et entreprend des mesures pour stopper la «roumanisation» (Nouzille, 2004: 290) de la République de Moldova. Le syntagme «langue moldave» reste souvent utilisé par le régime communiste de Chişinău. Le président, Vladimir Voronine a même ordonné en 2007, le remplacement de la dénomination «langue roumaine» par "moldave» dans les programmes scolaires. L'un des arguments destinés à soutenir sa virulente rhétorique anti-roumaine a été le fait que la langue moldave serait apparue avant la langue roumaine et qu'elle serait en fait la mère de la langue roumaine. L'appeler «roumaine» signifierait tromper l'histoire.

175 http://www.larousse.fr/encyclopedie/pays/Moldavie/133596

$176 \mathrm{http} / /$ assembly.coe.int/Documents/AdoptedText/ta02/FRES1280.HTM 
L'affirmation du processus de russification contribue au refroidissement des relations avec la Roumanie qui demande la révision du Traité de partenariat privilégié signé en avril 2001 et non encore ratifié. En effet, le pays reste ainsi un "champ privilégié des influences antagonistes de l'ancienne puissance titulaire: la Russie et du pôle d'attraction culturel et linguistique: la Roumanie» (Dulait, Boyer, Rouvière, 1999: 18). Le 28 juin 2001, la Moldova adhère au Pacte de stabilité pour l'Europe du Sud-Est et le 27 juill. 2001 à l'Organisation mondiale du commerce. En même temps, l'État moldave n'a pas pu empêcher les mouvements sécessionnistes, tant de la part des Slaves russes et ukrainiens de Transnistrie que des Gagaouzes habitant l'unité administrative de Gagaouze-Yeri.

\section{Région autonome : Gagaouzie}

Le 22 juillet 1990, le mouvement séparatiste "Gagaouze Halki» a

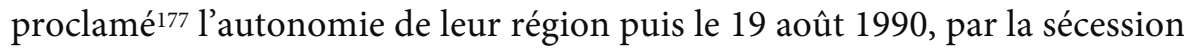
des trois districts Comrat, Ceadîr-Lunga et Vulcănești de la République socialiste soviétique de Moldavie, il a instauré une république socialiste soviétique de Gagaouzie «flanquée d'un Soviet suprême gagaouze " (Gangloff, $\left.1997:{ }^{178}\right)$ autour de la ville Comrat. Le 27 août 1991, la RSSM est devenue République de Moldova et de ce fait, la RSSG s'est autoproclamée république de Gagaouzie (Gagaouze-Yeri179) le 21 décembre 1991, justifiant que cette formation était le seul moyen de préserver son autonomie culturelle.

Cette aire géographique morcelée s'étendant sur $1800 \mathrm{~km}^{2}$, représentant 5,5\% ${ }^{180}$ du territoire de la République de Moldova avec une population de 155646 habitants $^{181}$ (Bureau National de Statistiques de la République de Moldova, 2006:39) regroupe 4,4\% du nombre total de locuteurs de Moldova (BNS de la RM, 2006: 300). Ils sont répartis entre les districts Basarabeasca, Ceadîr-Lunga, Comrat, Taraclia et Vulcanești.

Les ascendants des Gagaouzes, la tribu turque Oghouz, ont été identifiés pour la première fois dans l'histoire au XIII ${ }^{\mathrm{e}}$ siècle (Thedrel, 2009:182) dans

177 Un mois après la proclamation par la République de Moldova de sa souveraineté le 23 juin 1990

178 http://cemoti.revues.org/121\#bodyftn1

179 Signifie «lieux gagaouzes» en langue gagaouze

$180 \mathrm{http}: / /$ www.gagauzia.md/pageview.php?l=ro\&idc $=400$

181 dont 133477 Gagaouzes, 10702 Moldave 7811 Bulgares.

182 http://www.lefigaro.fr/international/2009/07/29/01003-20090729ARTFIG00299-il-estune-petite-republique-autonome-que-le-demon-du-separatisme-demange-.php 
la région nord-est de la Bulgarie, plus précisément dans la région de Varna (Encyclopédie universelle Russe, Brockhaus-Efron et Grande Encyclopédie soviétique, Lexique commun:183). C'est à cette époque que s'est produite l'ethnogénèse du peuple gagaouze (Comité Exécutif de la Gagaouzie:184), que ce dernier a constitué un groupe ethnique distinct et que la première formation étatique du peuple gagaouze, nommée Kay Ka'us: Gagaouzie, a été établie (Haro, 1999:185). Une partie de cette population a traversé le Danube (Encyclopaedia Universalis: ${ }^{186}$ ) et s'est installée dans la vallée de Budjak $^{187}$ en Bessarabie.

Les Gagaouzes constituent une communauté turcophone de confession chrétienne orthodoxe. Ils parlent gagaouze, une langue du sous-groupe oghouze occidental qui fait partie du groupe de langues turques (Karanfil, 2010: 5) et qui est rattachée à la famille des langues altaïques ${ }^{188}$. Jusqu'au milieu $\mathrm{du} \mathrm{xx}^{\mathrm{e}}$ siècle, la langue gagaouze était surtout orale, dépourvue d'alphabet écrit. Le 30 juillet 1957 un décret du Présidium du Soviet suprême de la RSS de Moldavie, a introduit l'écriture de la langue gagaouze basée sur l'alphabet cyrillique (Académie de sciences de l'URSS Institut de linguistique, 1966: 112.) Actuellement est officiellement utilisé l'alphabet basé sur la graphie latine. Ce peuple a gardé tout au long de plusieurs siècles, sa langue, sa culture et sa riche création populaire.

Au début des années 1970, dans l'Union soviétique, l'enseignement de la langue gagaouze a été complètement exclu du programme. Au niveau national, les livres et les manuels de langue gagaouze n'étaient pratiquement pas édités. Ainsi l'URSS menait une politique de russification qui fragilisait l'identité du peuple gagaouze, le coupant des éléments qui déterminent la constitution de son identité (ainsi la langue, la religion, la culture), l'assimilant à la «nation soviétique» (Académie de sciences de l'URSS Institut de linguistique, 1966: 113) et cette politique était la même face à beaucoup de petites nations de l'URSS.

Le Parlement moldave a reconnu aux Gagaouzes un statut d'autonomie en décembre 1995, proclamant la Gagaouze-Yeri comme une forme

183 http://gatchina3000.ru/big/018/18355_brockhaus-efron.htm

$184 \mathrm{http} / /$ www.gagauzia.md/pageview.php?l=ro\&idc $=400$

$185 \mathrm{http} / / /$ www.regard-est.com/home/breve_contenu.php?id=13

$186 \mathrm{http} / /$ www.universalis.fr/encyclopedie/gagaouzes/

187 dans les régions de Bender et d'Ismail

188 http://www.ethnologue.com/language/gag 
d'autodétermination ${ }^{189}$ des Gagaouzesfaisant partieintégrantedela République de Moldova. Elle lui a donné le droit de posséder ses propres symboles (un drapeau, un hymne, des armoiries) que l'on fait voisiner avec ceux de la Moldova dans les occasions et les lieux officiels. La Gagaouzie a obtenu aussi le droit de se doter d'une Assemblée législative et d'organes exécutifs spécifiques, lui permettant de définir, dans la limite de ses compétences, de décider elle-même des questions concernant le développement politique, économique, culturel dans l'intérêt de toute la population ${ }^{190}$. C'est une entité politique et nationale nantie de trois langues, le gagaouze, le moldave, le russe. Elle dispose d'un Journal officiel, «Nouvelles de Gagaouzie» où sont publiés décrets et résultats électoraux (Paul-Boncour, De Sinety, 2007: 9). Le 13 juillet 1995, le gouvernement de la République de Moldova ${ }^{191}$ a signé la Convention-cadre pour la protection des minorités nationales (Yacoub, 1995: 7) du Conseil de l'Europe ${ }^{192}$. L'article $1^{\text {er }}$ de la loi sur le statut juridique particulier de la Gagaouzie ${ }^{193}$ accorde des droits collectifs à la minorité gagaouze mais prévoit aussi une autodétermination qui ne remet pas en question l'intégrité territoriale de la Moldova. Néanmoins, en cas d'union politique avec la Roumanie par exemple, la Gagaouzie aurait théoriquement le droit d'accéder à l'indépendance (Haro, 1999:194). En 1998, un projet de constitution gagaouze a été soumis aux experts du Conseil de l'Europe par le président de l'Assemblée régionale.

Le 25 juillet 2003, la loi n ${ }^{\circ}$ 344-XV ${ }^{195}$ a modifié l'article 111 de la Constitution moldave ${ }^{196}$. Le statut spécial lui attribue des formes et conditions spéciales d'autonomie. Selon l'article $1^{\mathrm{er}}$, le titre $\mathrm{I}^{\mathrm{er}}$ : Statut juridique de la Gagaouzie dans le cadre de la République de Moldova ${ }^{197}$ du Règlement, la loi

189 L. sur le statut juridique spécial de la Gagaouzie, n³44-XIII, du 23 déc. 94, MO, $\mathrm{n}^{\circ} 3-4 / 51$, du 14 janv. 1995.

190 L. sur le statut juridique spécial de la Gagaouzie, n³44-XIII, du 23 déc. 94, MO, $\mathrm{n}^{\circ} 3-4 / 51$, du 14 janv. 1995.

$191 \mathrm{http} / /$ conventions.coe.int/treaty/fr/Treaties/Html/157.htm

192 Gouvernement de la RM. Rapport soumis par la RM en vertu de l'art. 25, al. 1, de la Convention-cadre pour la protection des minorités nationales, Chișinău, 29 juin 2000.

193 L. sur le statut juridique spécial de la Gagaouzie, n³44-XIII, du 23 déc. 94, MO, $\mathrm{n}^{\circ} 3-4 / 51$, du 14 janv. 1995, art. 1, al. 4.

194 http://www.regard-est.com/home/breve_contenu.php?id=13

195 L. sur le statut juridique spécial de la Gagaouzie, n³44-XIII, du 23 déc. 94, MO, $\mathrm{n}^{\circ} 3-4 / 51$, du 14 janv. 1995.

196 Constitution de la RM, du 29 juillet 1994, MO, nº 1, du 12 août 1994.

$197 \mathrm{http} / / /$ www.venice.coe.int/webforms/documents/CDL(1998)024rev-f.aspx 
Fondamentale de la Gagaouzie ${ }^{198}$, il s'agit d'une unité territoriale-autonome à statut juridique spécial reflétant le droit du peuple gagaouze à disposer de lui-même dans le cadre de la République de Moldova et en exerçant son activité en accord avec la Constitution de ce pays, la loi concernant le statut spécial juridique de la Gagaouzie, le Règlement et les actes de l'Assemblée populaire de la Gagaouzie.

\section{Région autoproclamée: Transnistrie}

La Transnistrie peuplée de 800000 habitants (17\% de la population moldave) ${ }^{199}$, dont 32\% Moldaves, 30\% Russes et 29\% Ukrainiens ${ }^{200}$ a connu à la fin des années 1980 un mouvement séparatiste refusant la dislocation de l'URSS (Ditter, Smessov, 1996: 6). Ce mouvement a conduit à la proclamation d'une indépendance le 2 septembre $1990^{201}$, date à partir de laquelle le gouvernement moldave n'a plus contrôlé l'ensemble de son territoire. Ex-république autonome, rattachée à la RSSM depuis 1940, la Transnistrie sécessionniste a fait appel à la Russie pour la soutenir, entraînant des affrontements armés sanglants en 1992. Le cessez-le-feu de juillet $1992^{202}$ a ensuite gelé la situation, le régime de Tiraspol s'érigeant en Etat de facto.

Il apparaît impossible de résoudre ce qui a été séparé par une guerre dont chacun accuse l'autre d'avoir pris l'initiative. Les Russes de Transnistrie

198 Appelé «Ulozhenie» (Code juridique) de la Gagaouzie.

199 Valcov V. ex-directeur de la Direction de la Statistique et de la sociologie a déclaré que «la Transnistrie ne respecte pas les recommandations internationales pour la réalisation d'un recensement et par conséquent, les données collectées en Transnistrie peuvent ne pas être saisies avec les données du reste de la Moldavie car elles ont été recueillies sans contrôle international.» Par conséquent, tous les chiffres du recensement ne comprennent pas les territoires qui sont sous contrôle des autorités de la Transnistrie. (Academic Dictionaries and Encyclopedias, voir http://dic.academic.ru/dic.nsf/enwiki/1875683)

200 Les autorités de la Transnistrie ont publié uniquement le pourcentage de groupes ethniques, le nombre d'individus a été calculé sur la base de ces pourcentages. Le nombre ou le pourcentage de personnes déclaré en Transnistrie comme «roumain» a été publié inclus dans la catégorie "Autres».

201 Avant même la disparition de l'URSS, Smirnov I. a pris la tête de la Transnistrie (1990), bénéficiant en 1991 de l'appui du général Lebed et de la 14e armée russe pour affronter les dirigeants de Chișinău.

202 Un armistice est toutefois signé le 21 juillet 1992 par les autorités moldaves et russes. Il comporte notamment la création d'une zone de sécurité démilitarisée et la constitution d'une force tripartite de 1200 hommes (Russes, Moldaves, Transnistriens) de maintien de la paix, placée sous la supervision politique d'une Commission conjointe de contrôle. La Russie dispose également d'un contingent chargé de sécuriser le dépôt de munitions héritées de la période soviétique entreposées à Colbasna. 
rendent responsables le nationalisme roumanophile des années 1989-1990 et les Moldaves évoquent plutôt leurs difficultés à affirmer leur mouvement de libération nationale face à l'hostilité ouverte des russophones de la rive gauche du Dniestr à l'égard de la réforme linguistique qui restaurait le moldave comme langue nationale avec graphie latine.

L'administration de cette région ${ }^{203}$ officiant en russe, impose sa loi aux Moldaves de la région, fait obstacle à toute tentative de conciliation et demeure radicalement opposée à toute réunification avec la Roumanie. La politique de déroumanisation s'y poursuit et aucune solution n'est en vue.

Elles constituent un véritable reliquat du régime "conservatoire soviétique», décrit par le journaliste et essayiste tchèque Palata L. «[...] La faucille et le marteau ornent toujours le blason de la Transnistrie [...] devant le siège du gouvernement trône un gigantesque Lénine de granit et, au beau milieu de l'avenue principale de ville Tiraspol, git un tank soviétique que jouxte le cimetière des héros». C'est l'Union soviétique enfermée dans un bocal, qui aura su résister aux vingt ans de bouleversements survenus depuis l'effondrement de l'«empire du mal» (Palata, $2007:{ }^{204}$ ).

Tout au long des années qui suivront, diverses tentatives se sont succédées pour tenter de résoudre le conflit. Un projet de fédéralisation de la République de Moldova a été proposé par les autorités séparatistes aux termes duquel la Transnistrie optait pour «son indépendance» contestant le caractère unitaire de la Moldova. Selon $\mathrm{H}$. Collet, le régime séparatiste de Tiraspol est très efficace dans la poursuite de ses buts. Par exemple, en 1996, il a obtenu le droit de commercer avec l'étranger en utilisant les scellés fournis par la République de Moldova. En 1997, le célèbre mémorandum signé par le président moldave P. Lucinschi et le président autoproclamé I. Smirnov lui a garanti un statut paritaire dans la construction d'un «État commun ${ }^{205}$. En 2002, il a poussé les autorités moldaves à accepter que l'État réunifié soit une fédération. En 2003, grâce au plan de règlement russe dit mémorandum Kozak, il était sur le point d'être reconnu en tant qu' État avec le droit de poser son veto dans la fédération à venir, tout en occupant un tiers des sièges, bénéficiant d'un grand nombre de garanties fournies par

203 Elle est tenue par un conglomérat d'anciens du KGB, d'officiers recyclés de l'armée soviétique et de mafieux.

204 http://www.courrierinternational.com/article/2007/10/25/la-moldavie-existe-j-enreviens

205 Le mémorandum prévoyait l'ouverture des frontières, l'utilisation du Leu comme monnaie unique, l'harmonisation des législations et le retrait de la $14^{\mathrm{e}}$ armée russe. 
la Fédération de Russie ${ }^{206}$. Mais le Président Voronine refuse à la dernière minute de signer le texte, comprenant que l'acceptation de ce modèle pouvait amener à la disparition du pays en tant qu'État. Par conséquent, le projet de retrait militaire russe a été abandonné

Face au blocage des négociations, le président moldave cherche à partir de l'automne 2003, à internationaliser la gestion du conflit et invite la Roumanie, l'Union européenne et les États-Unis à s'impliquer. Les partis qui revendiquent la roumanophonie, minoritaires, estiment que toutes ces propositions visent en réalité à russifier la République de Moldova dans sa totalité. Si elles sont adoptées, se produira en fait «une annexion de la Moldova par la république moldave du Dniestr ${ }^{207}$. Pour sa part, l'État moldave s'est lancé dans la surenchère particulariste et tend à se différencier au maximum de l'État roumain.

Pour le moment, la République moldave de Transnistrie reste une véritable entité étatique, sans reconnaissance officielle internationale même de la part de la Russie. Dotée de tous les attributs d'un État, elle tente de forger une identité nationale pour justifier son existence (Parmentier, 2007: $\left.69^{208}\right)$, au-delà de sa réputation de carrefour de la contrebande et des trafics de tous genres (armes, cigarettes, alcool, produits pétroliers, être humains). Quant à la vie politique, elle est concentrée entre les mêmes mains que la vie économique (Despic-Popovic, 2002:209), malgré un certain pluralisme de façade. Dans ces conditions, nous pouvons nous demander si les élites transnistriennes n'ont pas plutôt intérêt au maintien du statu quo, qui leur permet de ne rendre de comptes à personne. La dernière tentative d'autolégitimation fut le référendum illégal de septembre 2006, qui approuva à plus de 90 \% l'indépendance, la non-appartenance à la Moldova et le projet de rattachement à la Russie. Cette dernière y maintient toujours une unité de l'armée russe, faisant de la Transnistrie un moyen de pression dans ses négociations avec la communauté internationale sur le statut de cette région.

La proclamation unilatérale de l'indépendance par la province du Kosovo $^{210}$ vis-à-vis de la Serbie le 17 février 2008, a suscité de profondes

206 http://www.colisee.org/article.php?id_article=1206

207 Déclaration de Iurie Rosca au VIII e congrès du PPCD.

208 http://www.operationspaix.net/DATA/DOCUMENT/5443 V La_Transnistrie_politique_ de_legitimite_d_8217un_Etat_de_facto_.pdf

$209 \mathrm{http}: / /$ www.liberation.com/page.php? Article $=45119$

210 Province serbe qui compte 2 millions d'habitants, dont $90 \%$ sont Albanais. 
préoccupations en Moldova et elle a été suivie avec grand intérêt en Transnistrie. Les dirigeants de cette dernière, soutenus par la Russie, qui a intérêt à maintenir le statu quo dans le conflit transnistrien, considéraient que le fait constituait un précédent justifiant leur propre aspiration à la sécession. Comme la Russie fait face au territoire sécessionniste de la Transnistrie, elle a mis en garde contre le précédent que pourrait représenter l'indépendance du Kosovo dans les territoires sécessionnistes (Déners, 2008:211). Le gouvernement moldave attaché au principe de l'intégrité territoriale des États, exclut de reconnaître une indépendance du Kosovo susceptible d'avoir un impact sérieux sur le conflit en Transnistrie, considérant que cela reviendrait à confirmer la possibilité d'un changement des frontières. Dans l'immédiat, il est peu probable que la Russie reconnaisse formellement l'indépendance de la Transnistrie. Elle va davantage renforcer ses relations avec Tiraspol, compte bien utiliser le précédent du Kosovo et la menace de nouvelles sécessions pour renforcer ses positions diplomatiques.

Confrontés au dilemme de leur devenir économique, l'État moldave et la Transnistrie, tous deux "préoccupés par la reconstruction de l'avenir» (Dressler, 1999: 217) sont orientés par la Russie vers une réintégration au sein de la CEI. L'évolution de la situation intérieure politique des deux entités rend sans doute improbable à court terme, une réunification politique. En général, la classe politique moldave préfère poursuivre un certain équilibre tant envers la Russie qu'envers la Roumanie, ce qui semble «un gage de la stabilité intérieure de la République de Moldova» (Goujon, 2004: 9).

Suite au dernier élargissement de 2007, l'Union européenne possède une nouvelle frontière orientale ce qui crée de nouveaux enjeux et soulève déjà de nombreuses questions. La position de la Moldova est d'autant plus délicate sur cette nouvelle carte que ses débouchés vers l'Est (Communauté d'États Indépendants) passent obligatoirement par la Transnistrie, ce qui fragilise ses échanges. La République de Moldova est un pays aux frontières de l'Union Européenne, totalement isolé, faiblement industrialisée, en raison du fait que la Transnistrie concentre la plus large part du potentiel industriel (Mongrenier, 2009: 1).

\section{Conclusion}

La Moldova est un vieux pays européen. La Principauté de Moldavie, est un État unitaire, créé au XIv siècle, qui dès sa fondation a dû faire face 
à la politique expansionniste de ses puissants voisins, est devenue une force politique importante du Sud-Est de l'Europe au XIV siècle. Sa population parlait une langue latine, dont «le dénominateur commun a été la langue roumaine moderne» (Nouzille, 2004: 339), fixée sous sa forme littéraire au $\mathrm{XVII}^{\mathrm{e}}$ siècle. En 1812, la Russie tsariste occupe la partie orientale de la Principauté de Moldavie et la transforme en goubernia russe, appelé Bessarabie. En 1918, elle décide de s'unir à la Roumanie de 1918 à 1940 et de 1941 à 1944, ayant le statut de région roumaine. Mais, elle est annexée à l'Union soviétique de 1940 à 1941 et entre 1944 et 1991, formant la République socialiste soviétique de Moldavie. À cette époque le pouvoir soviétique met en place les processsus de déroumanisation et de russification, imposant l'alphabet cyrillique à la «langue reconnue officiellement comme moldave» et le russe obtient le statut de langue de communication interethnique.

Après la proclamation de son indépendance, en 1991, la République de Moldova est confrontée à des problèmes internes ethniques et territoriaux, qui ont amené à la sécession de la Gagaouzie et de la Transnistrie. Aux termes de la Constitution de la République de Moldova du 29 juillet 1994212: «La langue d'État de la République est la langue moldave utilisant la graphie latine», l'État reconnaît et protège le droit à la conservation, au développement et à l'utilisation de la langue russe et des autres langues sur le territoire du pays. Au lieu de créer une identité commune à tous les citoyens, l'État reconnaît et garantit à tous les citoyens le droit de conserver, de développer et d'exprimer leur identité ethnique, culturelle, linguistique et religieuse.

Si l'histoire de la Moldova a été partagée entre la Russie et la Roumanie, sa viabilité semble dépendre des relations entre la Russie et l'Union européenne (Parmentier, 2003: 141).

La Moldova, pays d'Europe centrale et orientale, ne fait pas partie de la «nouvelle Europe», mais de l'autre Europe, celle de l'Est.

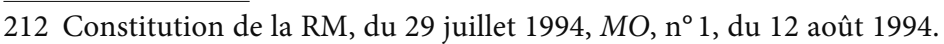




\section{Bibliographie}

Academic Dictionaries and Encyclopedias http://dic.academic.ru/dic.nsf/enwiki/1875683

Académie de sciences de l'URSS. Institut de linguistique. 1966, Языки народов СССР в 5-ти томах. Тюркские языки (Les langues des peuples de l'URSS en 5 volumes. Langues turques), tome 2, Moscou, Nauka.

Andreescu A., 2007, «Quelques références sur l'art de l'imprimerie roumaine aux $\mathrm{XVI}^{\mathrm{e}}$ et $\mathrm{XVII}^{\mathrm{e}}$ siècles", Revista Bibliotecii Naționale a României, année XIV, $\mathrm{n}^{\circ} 27$, 1/2008: 8-11, voir http://www.bibnat.ro/dyn-img/publicatii/Revista_BNR_1_2008COMPLETA.pdf

Aramă E., 2003, Istoria dreptului românesc (Histoire du droit roumain), Chișinău, Reclama.

Baggioni D., 1994, Langues et nations en Europe, Paris, Payot et Rivage.

Batuchkov P. N., 1892, Бессарабия: Историческое описание (Bessarabie:Description historique), Saint-Pétersbourg, Éditions de Association «Utilité publique».

Berg L.S., 1918, Бессарабия. Страна, люди, хозяйство (Bessarabie. Pays, gens, économie), Pétrograde, Ogni.

Berg L. S., 1923, «Население Бессарабии. Этнографический сотав и численность » («Population de la Bessarabie - composition et nombre ethnographique»), in: Travaux de la commission pour l'étude de la composition ethnique de la population de Russie, Pétrograde, Ogni.

Bergmann F.-G., 1859, Les Gètes ou la filiation généalogique des Scythes aux Gètes et des Gètes aux Germains et aux Scandinaves démontrée sur l'histoire des migrations de ces peuples et sur la continuité organique des phénomènes de leur état social, moral, intellectuel et religieux, Strasbourg, Chez Treuttel et Würtz. Libraires. Paris, Chez F. Jumg-Treuttel.

Berindei D., 2003, «Constantin le Grand et les Roumains», Rivista Internazionale di Scienze Giuridiche et Tradizione Romana, $\mathrm{n}^{\circ} 2$, voir http://www.dirittoestoria.it/ memorie2/Testi\%20delle\%20Comunicazioni/Berindei-Constantin-Le-Grand.htm

Berindei M., Thedrel A., 2003, «Moldova un désir d'Occident?», Politique internationale, $\mathrm{n}^{\circ} 99$, voir http://www.politiqueinternationale.com/revue/read2.php?id_revue $=14$ \&id=200\&search=\&content=texte

Boca-Bordei R., 2002, "La latinité - repère identitaire roumain», in Mythes et symboles politiques en Europe Centrale, Paris, PUF.

Boldur A., 2000, Basarabia si relațiile româno-ruse: Chestiunea Basarabiei şi dreptul internațional (La Bessarabie et les relations roumaino-russes: la question de la Bessarabie et le droit international), Bucureşti, Albatros.

Botsan I., 2004, «Moldavie: bilan de trios années d'efforts pour essayer de régler le conflit transnistrien», 25.04.2004, Colisee, voir http://www.colisee.org/article. php?id_article $=1206$

Bratianu G.I., 1995, Basarabia. Drepturi naționale și istorice (Bessarabie. Droits nationaux et historiques), București, Semne. 
Bruchis M., 1999, Republica Moldova: Quo vadis?: oportunism, naționalism, șovinism (République de Moldova: Quo vadis?: opportunisme, nationalisme, chauvinisme), Bucureşti, Editura Fundației culturale române.

Bugai N., 2004, «Депортация народов» («Déportation des peuples»), in: Война и общество. 1941-1945 (Guerre et société. 1941-1945), Livre II, Moscou, Nauka, voir http://ic.pics.livejournal.com/skladkartinok/37897754/219892/219892_ original.jpg

Bureau National de Statistiques de la République de Moldova, 2006, Recensământul populației din 2004 (Recensement de la population de 2004), volume I, Chișinău, Statistica, voir http://www.statistica.md/public/files/publicatii/Recensamint_vol1.jpg Bureau of Democracy, Human Rights, and Labor of US Department of State, 2004, County Reports on Human Rights Practices. Moldova, voir http://www.state.gov/g/ $\mathrm{drl} / \mathrm{rls} / \mathrm{hrrpt} / 2004 / 41697 . \mathrm{htm}$

Buse I., 2008, «Les Roumains entre les mythes nationaux et le mythe de l'Europe politique», Revue internationale de philosophie en ligne, novembre 2008, année III, numéro 6, voir http://www.metabasis.it/articoli/6/6_Buse.pdf

Cantemir D., 1981, Hronicul vechimii româno-moldo-vlahilor (L'historique de l'ancienneté des Roumano-moldo-vlaches), București, Albatros.

Cantemir D., 2001, Descrierea Moldovei (Description de la Moldavie), București, Litera International. Chişinău, Litera, voir http://cantemird.files.wordpress.com/2008/03/ cantemir-dimitrie-descrierea-mold.pdf

Caraman P., 2007, "Românitatea Basarabiei văzută de ştiința oficială sovietică » («La romanité de la Bessarabie vue par la science officielle soviétique»), Bulletin Scientifique du Musée national d'Ethnographie et d'Histoire naturelle de Moldova, $\mathrm{n}^{\circ} 7$ (20), 2007: 14-33.

Carriere d'Encausse H., 1990, La gloire des nations ou la fin de l'Empire soviétique, Paris, Fayard.

Casso L.A., 1913, Россия на Дунае и образование Бессарабской области (Lа Russie sur le Danube et l'éducation dans la région de Bessarabie), Moscou, Lycée impérial.

Castellan G., 2004, Histoire des Balkans, Paris, Fayard.

Caşu I., 2000, "Politica națională" în Moldova sovietică. 1944-1989 (Politique nationale en Moldavie soviétique. 1944-1989), Chișinău, Cartdidact.

Caterly J., 1908, Les Roumains, tome 1 1er, Paris, Calmann-Lévy Editeurs, voir http://www.archive.org/stream/lesroumainstomep00stiruoft\#page/n5/mode/2up

Călinescu G., 1997, Istoria literaturii române de la origini până în prezent (Histoire de la littérature roumaine des origines à nos jour)s, București, Litera, voir http:// www.scribd.com/doc/389126/Istoria-literaturii-romane-de-la-origini-pana-inprezent-1 
Chauvier J.-M., 2011, "Il y a vingt ans en URSS. L'épreuve de force décisive des 18-21 août 1991 », Le Monde diplomatique, 23 août 2011, voir http://www.mondediplomatique.fr/carnet/2011-08-23-URSS

Chirițescu C., 1988, Istoria războiului pentru integrarea României (Histoire de la guerre pour l'intégration de la Roumanie), volume VIII, Bucureşti, Editura Militară.

Chițimia I. C., Toma S., 1984, Crestomație de literatură română veche, volume I, Cluj-Napoca, Editura Dacia, voir http://archive.org/stream/CrestomatieDeLitera turaRomanaVechevol.1\#page/n1/mode/2up

Cihodaru C., 1984, Alexandru cel Bun. 23 aprilie 1399 - 1ianuarie 1432 (Alexandre le

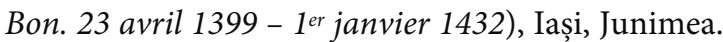

Ciobanu Ş., 1924, Dimitrie Cantemir în Rusia (Dimitrie Cantemir en Russie), Bucureşti, Cultura Naţională.

Ciocanu I., 2004, «Îndemn şi contribuție» («Ehxortation et contribution»), Littérature et Art, n 33 (3077), 19 août 2004: 3.

Clark Ch.U., 1927, Bessarabia, Russia and Roumania on the Black Sea, New York, Dodd, Mead and Company, voir http://depts.washington.edu/cartah/ text_archive/clark/bc_18.shtml

Costin M., 1886, De neamul moldovenilor. Din ce țară au iesșit strămoșii lor. (De la race des Moldaves. De quel pays sont leurs ancêtres), titre VI, voir http://ro.wikisource. org/wiki/De_neamul_moldovenilor

Costăchel V., Panaitescu P.P, Cazacu A., 1957, Viața feudală în Țara Românească și Moldova. Secolele XIV-XVI (Vie féodale en Pays roumain et moldave. XIV ${ }^{e}-X V I^{e}$ siècles), Bucureşti, Editura Ştiințifică.

Courtois S., Panne J.-L., 2005, « 8-9 mai 1945: contre le détournement de l'histoire», Le Figaro, 8 mai 2005: 3.

Danilevski N.Y., 2002, Россия и Eвроnа (La Russie et l'Europe), Moscou, Centre d'éditions «Ancien et Moderne», voir http://monarhiya.narod.ru/DNY/dny-list.htm

Danilov M., 2011, «About Macarie's Liturghier (1508), discovered in Bessarabia at the end of xixth-century (the book we have to know everything about)", in: Bibliothèque Métropolitaine Bucarest, Travaux de symposium international, Le Livre. La Roumanie. L'Europe, 3e éd., 20-24 septembre 2010, tome I, La première section - L'Histoire et la civilisation du livre, Bucarest, Editeur de la Bibliothèque de Bucarest, p. 67-73, voir http://www.bibmet.ro/Uploads//9_2011/120724.pdf

Deners J.-A., 2008, «Kosovo: l'indépendance et après?», Le Monde diplomatique, 17 février 2008, voir http://www.monde-diplomatique.fr/carnet/2008-02-17-Kosovo

Densusianu O., 1901, Histoire de la langue roumaine, tome $1^{\mathrm{er}}$ : Les origines, Paris, Ernest Leroux Editeur.

Despic-Popovic H., 2002, «La Transnistrie: Sovietic Park», Libération, 1 ${ }^{\mathrm{er}}$ août 2002, voir http://www.liberation.com/page.php?Article $=45119$

Ditter J.-G., Smessov S., 1996, Moldova, Paris, Centre Français du Commerce Extérieur (CFCE). 
Drăguicescu D., 1995, Din psihologia poporului român (De la psychologie du people roumain), Bucuresti, Albatros, voir http://www.scribd.com/doc/11445877/DDraghicescu-Din-psihologia-poporului-roman

Dressler W., 1999, Le second printemps des nations: sur les ruines d'un empire, questions nationales et minoritaires en Pologne (Haute-Silésie, Biélorussie polonaise), Estonie, Moldova, Kazakhstan, Bruxelles, Emile Bruylant.

Dressler W., 2005, "Entre empires et Europe le destin tragique de la Moldavie», Diogène, numéro 210, février 2005: 34-58, voir http://www.cairn.info/revuediogene-2005-2-page-34.htm

Durandin G., 2003, «Les protocoles “annexes” du pacte germano-soviétique. Un secret entretenu pendant cinquante ans", Histoire et Géographie, ${ }^{\circ}$ 382, mars 2003: 389-402, voir http://www.diploweb.com/forum/gdurandin2.pdf

Eliade M., 1943, Românii, latinii Orientului (Les Roumains, les latins de l'Orient), Lisboa, Livraria Clássica Editora.

Encyclopaedia Universalis, voir http://www.universalis.fr/encyclopedie/gagaouzes/

Encyclopédie universelle Russe, Brockhaus-Efron et la Grande Encyclopédie soviétique. Llexique commun. Варна (Varna), voir http://gatchina3000.ru/big/018/18355_ brockhaus-efron.htm

Epure V.-A., 2007, "Quelques considérations sur les relations entre la Moldavie et les tatars le long $\mathrm{du} \mathrm{Xv}^{\mathrm{e}}$ siècle de la perspective des sources historiques", Codrul Cosminului, numéro 13, p. 57-75, voir http://atlas.usv.ro/www/codru_net/ CC13/04_epure_violeta.pdf

Galben A., 2003, De l'histoire du droit féodal de la Moldova du XVIII au XIX ${ }^{e}$ siècle, Chișinâu, ULIM.

Gangloff S., "L'émancipation politique des gagaouzes, turcophones chretiens de Moldavie», Cahiers d'études sur la Méditerranée orientale et le monde turcoiranien, 23/1997, voir http://cemoti.revues.org/121\#bodyftn1

Georgescu V., 1992, Istoria românilor: De la origini până în zilele noastre (Histoire des Roumains: Dès origines à nos jours), Bucureşti, Humanitas.

Ghervas S., 2005, "La réinvention de l'identité moldave après 1989», Regard sur l'Est, 9 août 2005, voir http://www.regard-est.com/home/breve_contenu.php?id=367

Gheție I., 1974, Inceputurile scrisului în limba română. Contribuții filologice și lingvistice (Les débuts de l'écriture en langue roumaine. Contributions filologiques et linguistiques), București, Editura Republicii Socialiste România.

Ghibu O., 1996, Trei ani pe frontul Basarabean. Bilanțul unei activități (Trois années sur le front Bessarabe. Bilan d'une activité), București, Editura Fundației Culturale Române.

Ghibu O., 1997, De la Basarabia rusească la basarabia românească (De la Bessarabie russe à la Bessarabie roumaine), București, Semne.

Giuescu C., 2000, Istoria Românilor. 1352-1606 (Histoire des Roumains. 1352-1606), volume II, București, Editura Ştiințifică şi Enciclopedică, 
Goanec M., 2009, "Qui suis-je? Il paraît que je suis transnistrien », Libération, 6 avril 2009, voir http://www.liberation.fr/monde/0101560393-qui-suis-je-il-parait-queje-suis-transnistrien

Goga M., 2006, Une île de latinité: Culture, civilisation, langue et littérature roumaines, Paris, Presses de l'Université Paris-Sorbonne.

Goga M., 2007, La Roumanie. Culture et civilisation, Paris, Presses de l'Université de Paris-Sorbonne, voir http://books.google.fr/books?id=FidgbTQ414QC\&pg=RA3PT90\&lpg=RA3-PT90\&dq=D. +Din + psihologia + poporului + roman $+\%$ $5 \mathrm{BDe}+\mathrm{la}+$ psychologie $+\mathrm{du}+$ people + roumain \& source $=$ bl\&ots $=\mathrm{u}-\mathrm{LlAIiG}-$ Eb\&sig=gZGetN7U9ihEgLEck-y1cnTdZns\&hl=fr\&ei=YYzpTezDFJS38QOukJ2 $2 \mathrm{AQ} \& \mathrm{sa}=\mathrm{X} \& \mathrm{i}=$ book_result\&ct $=$ result\&resnum $=1 \& \mathrm{ved}=0 \mathrm{CB} 4 \mathrm{Q} 6 \mathrm{AEwAA} \# \mathrm{v}=\mathrm{o}$ nepage \&q\&f=false

Gorbatchev M., 1987, Перестройка и новое мышление для нашей страны и для всего мира (Restructuration et nouvelle pensée pour notre pays et pour le monde), Moscou, Politizdat.

Gore P., 1992, "Discours au Premier congrès des professeurs moldaves. 25-28 mai 1917 », Cugetul, numéro 4: 51-54.

Gorodetsky G., 1997, «Retour sur la préparation de la Seconde guerre mondiale. Les dessous du pacte germano-soviétique», Le Monde Diplomatique, juillet 1997: 4.

Goujon A., 2004, «Les nouveaux voisins de l'Union européenne. Stratégie identitaires et politiques en Ukraine, Biélorussie et Moldavie», Les Études du CERI, n 109, septembre 2004: 3-39.

Grünenwald F., Rieu A., 2008, «La Transnistrie», Diplomatie, numéro 30, janvierfévrier 2008: 4.

Harea V., 1995, Basarabia pe drumul unirii: Amintiri si comentarii (Bessarabie sur le chemin de l'unification), București, Editura Eminescu.

Haro F., 1999, «Les Gagaouzes», Regard sur l'Est, 1 avril 1999, voir http://www.regardest.com/home/breve_contenu.php?id=13

Heitmann K., 1998, Limbă și politică în Republica Moldova (Langue et politique en République Moldova), Chişinău, Arc.

Iancu V., 2005, «Conséquences linguistiques de la colonisation romaine de la Dacie», Linguistique. Bulletin scientifique, fascicule Filologie, série A, volume XV: 7-11, voir http://llr.ubm.ro/files/BS\%20LLR\%20XV\%202005.pdf

Iorga N., 1920, Istoria românilor și a civilizației lor (Histoire des Roumains et de leur civilisation), Paris, Henry Paulin Editeur, voir http://www.scribd.com/doc/7901485/ Iorgahistoire-Des-Roumains

Isopescu C., 1929, «Notizie intorno ai Romeni nella litteratura geografica italiana del cinquecento ", Bulletin de la Section Historique, volume XVI: 1-90.

Joudiou B., 1998, «Les principautés roumaines de Valachie et de Moldavie et leur environnement slavo-byzantin ", Balkanologie, volume 2, numéro1, juillet 1998, voir http://balkanologie.revues.org/index191.html 
Karanfil G., 2010, Parlons gagaouze, Paris, L'Harmattan, voir http://books.google.fr/ books?id=9eEzb7-S1B4C\&printsec $=$ frontcover \&dq=gagaouze\&hl=fr\&sa $=$ X\&ei $=$ oalPUeucC-qN7Qbz3YCQCQ\&ved=0CDIQ6AEwAA

Karlinsky B., «"Les Cosaques”: Les Cosaques, ces Vendéens de la révolution russe», Libération, 4 février 1995, voir http://www.liberation.fr/medias/0101132609-lescosaques-les-cosaques-ces-vendeens-de-la-revolution-russe

King Ch., 1997, «Politique panroumaine et identité moldave», Balkanologie, volume I, $\mathrm{n}^{\circ} 1$, juillet 1997, voir http://balkanologie.revues.org/index195.html

King Ch., 2005, Moldovenii. România, Rusia și politica culturală (Les Moldaves. La Roumanie, la Russie et la politique culturelle), Chișinău, Arc.

Kogălniceanu M., 1837, Histoire de la Valachie, de la Moldavie et des Valaques transdanubiens, tome $1^{\mathrm{er}}$ : Histoire de la Dacie, des Valaques transdanubiens et de la Valachie (1241-1792), Berlin, Librairie B. BEHR, voir http://books.google.fr/bo oks?id=1B4FAAAAYAAJ\&printsec=frontcover\&hl=fr\&source=gbs_ge_summar y_r\&cad $=0 \# \mathrm{v}=$ onepage $\& \mathrm{q} \& \mathrm{f}=$ false

Kouropatkine A.B., 1910, Задачи русской армии (Objectifs de l'armée russe), St-Pétérsbourg, DGEM.

Krouchevan P., 1903, Альманах Бессарабия. Графический, исторический, статистический, экономическиц̆, этнографический, литературныци и справочный сборник (Almanache de Bessarabie. Recueil graphique, historique, statistique, économique, ethnographique, littéraire et informatif), Moscou, Typographie, voir http://oldchisinau.com/lib/bessarabia/bessarabia5.html

Laignel-Lavastine A., 2002, Cioran, Eliade, Ionesco: l'oubli du fascisme: trois intellectuels roumains dans la tourmente $d u$ siècle, Paris, PUF, voir http:// pagesperso-orange.fr/relation.douce/FrAct/Cioran.htm

Larousse, Moldova (Moldavie), voir http://www.larousse.fr/encyclopedie/pays/ Moldavie/133596

Ledermann S., 1948, "La République populaire de Roumanie», Population, année III, $\mathrm{n}^{\circ}$ 3: 571-574, voir http://www.persee.fr/web/revues/home/prescript/article/ pop_0032-4663_1948_num_3_3_1969

Lénine V.I., 1968, «Социалистическая революция и право наций на самоопределение: Тезисы. 1916» («La révolution socialiste et le droit des nations à disposer d'elles-mêmes. Thèses $1916 »)$, in: Questions de la politique nationale et de l'internationalisme prolétarien, Moscou, Progrès.

Marinescu-Nicolajsen L., 1999, «La Colonne Trajane: le triptyque de la victoire. Contribution a une nouvelle interprétation de la scène IX", Mélanges de l'École française de Rome. Antiquité, volume 111, n 111/1:273-310, voir http://www.persee. $\mathrm{fr} / \mathrm{web} / \mathrm{revues} / \mathrm{home} / \mathrm{prescript/article/mefr}$ _0223-5102_1999_num_111_1_2079

Matei H., Nicolae I., Negut S., Radu C., 2005, Enciclopedia statelorlumii (L'encyclopédie des États du monde), 7e édition, București, Meronia.

Mateevici A., 1993, Opere (Oeuvres), volume Ier, Chişinău, Ştiința. 
Millot L., 2009, "Chișinău sous emprise roumaine», in Libération, 16 avr. 2009. http://www.liberation.fr/monde/0101562283-chisinau-sous-emprise-roumaine

Mongrenier J.-S., 2009, La Moldavie, «angle mort» de l'Europe?, Institut Thomas More, 14 avril 2009: 1-8, voir http://www.institut-thomas-more.org/upload/media/ jsmongrenier-avril2009.pdf

Moceanu O., 2002, Literatura română veche (La littérature ancienne roumaine), Brașov, Éditions de l'Université "Transilvania», voir http://www.scribd.com/ doc/23327065/Ovidiu-Moceanu-Literatura-Romana-Veche

Moraru A., 2004, «Ocupația sovietică. 24 august 1944» («Occupation soviétique: 24 août 1944»), Littérature et Art, n³3 (3077), 19 août 2004: 3.

Munteanu I., 2010, Les Partis politiques de la République de Moldova, Chișinău, Cartier.

Naudet J.-B., 1991, «La proclamation d'indépendance de la Moldavie, “étape avant la réunification" avec la Roumanie», Le Monde, 29 août 1991: 5.

Negură P., 2009, "L'invention de la langue moldave: nationale ou soviétique?», Regard sur l'Est, 27 mars 2009, voir http://www.regard-est.com/home/breve_ contenu.php?id=943\&PHPSESSID $=014747 \mathrm{a} 3 \mathrm{f} 45 \mathrm{~d} 7 \mathrm{~b} 30 \mathrm{e} 147 \mathrm{bf} 70 \mathrm{c} 65 \mathrm{a} 2 \mathrm{ae} 3$

Negură P., 2011, «La Transnistrie : les origines d'un conflit gelé», Grotius International. Géopolitiques de l'Humanitaire, 27 octobre 2011, voir http://www.grotius.fr/ la-transnistrie-les-origines-dun-conflit-gele/

Nouzille J., 2004, La Moldavie: histoire tragique d'une région européenne, Huningue, Bieler.

Palata L., 2007, «Aux confins de l'Europe. La Moldova existe, j'en reviens », Courrier international, numéro 886, 25 octobre 2007, voir http://www.courrierinternational. com/article/2007/10/25/la-moldavie-existe-j-en-reviens

Parmentier F., 2003, La Moldova à la croisée des chemins, Paris, Universitoo.

Parmentier F., 2006, «La Moldova et la Transnistrie. Géopolitique du voisinage euro-russe», La revue géopolitique, 1 avril 2006, voir http://www.diploweb.com/ La-Moldavie-et-la-Transnistrie.html

Parmentier F., 2007, «La Transnistrie. Politique de légitimité d'un État de facto», Le courrier des pays de l'Est, numéro 1061, 2007/3: 69-75, voir http://www. operationspaix.net/DATA/DOCUMENT/5443 v La_Transnistrie_politique_de_ legitimite_d_8217un_Etat_de_facto_.pdf

Paul-Boncour M., De Sinety P., 2007, Voyage au pays des Gagaouzes, Paris, Cartouche. Pippidi A., 1996, «Identitate etnoculturală în spațiul românesc. Probleme de metodă » ("Identité ethnoculturelle dans l'espace roumain. Problèmes de méthode»), in ZUB A., Identitate/alteritate în spațiul cultural romînesc (Identité/altérité dans l'espace culturel roumain), Iaşi, Université Alexandru Ioan Cuza.

Pittard E., 1917, La Roumanie. Valachie - Moldavie, Dobroudja, Paris, Bossard.

Reclus E., 1876, Nouvelle Géographie Universelle, La Terre et les Hommes, tome Ir: L'Europe Méridionale, (Grèce, Turquie, Roumanie, Serbie, Italie, Espagne et 
Portugal), titre V: Les Races et les peuples, Paris, Librairie Hachette et Cie, voir http://www.gutenberg.org/files/28370/28370-h/28370-h.htm\#footnote1

Repida A.V., 1983, Formarea R.S.S. Moldovenești (Création de la R.S.S. Moldave), Chişinău, Cartea Moldovenească.

Réseau francophone de recherche sur les opérations de paix, Historique de l'opération $P K F$. Force conjointe de maintien de la paix sur la frontière moldavo-transnistrienne, voir http://www.operationspaix.net/136-historique-pkf.html

Ruzé A., 1997, La Moldova entre la Roumanie et la Russie: de Pierre le Grand à Boris Eltsine, Paris, L'Harmattan.

Ruzé A., 1999, Ukrainiens et Roumains. IX ${ }^{e}-X X^{e}$ siècles. Rivalités carpatho-pontiques, Paris, L'Harmattan.

Sarov I., Cusco A., 2001, «Identitatea națtională a basarabenilor în istoriografia rusă din secolul XIX» (Identité nationale des bessarabes dans l'historiographie russe du XIX $^{\mathrm{e}}$ siècle), in: Solomon F., Zub A., Basarabia. Dilemele identității (Bessarabie. Dilèmes de l'identité), Iaşi, Éditions de l'Université Alexandru Ioan Cuza.

Serbesco S., 1918, La Roumanie et la guerre, Paris, Armand Colin, voir http://archive.org/stream/laroumanieetlagu00serbuoft\#page/50/mode/2up

Serebrian O., 2006, Va exploda Estul?: Geopolitica spațiului pontic (L'Est va exploser?: La géopolitique de l'espace pontique), Chişinău, Cartier.

SIL International, Ethnologue. Languages of the world, Gagauz (Gagaouzie), voir http://www.ethnologue.com/language/gag

Silaşi G., 1879, «Renascerea limbei romanesci in vorbire sî scriere ( «Renaissance de la langue roumaine dans l'expression orale et à l'écrit»), Amiculu familiei. Foia biseptemenaria pentru toate trebuințele vieții sociale, Gherla et Clusiu, 1/13 mai 1879, numéro 9: 1-92, voir http://documente.bcucluj.ro/web/bibdigit/periodice/ amiculufamiliei/pdf/BCUCLUJ_FP_279056_1879_002_009.pdf

Sișcanu I., Văratic V., 1991, Pactul Ribentrop-Molotov şi consecințele lui pentru Basarabia. Culegere de documente (Pacte Ribbentrop-Molotov et ses conséquences pour la Bessarabie. Recueil de documents), Chișinău, Universitas.

Şişcanu I., 1992, «Formarea și evoluția R.A.S.S.M. : de la 1924 la 1940 » ( Formation et évolution de la R.A.S.S.M.: de 1924 à $1940 »)$, Cugetul, numéros 5-6: 62.

Skalkovskii A.A., 1838, Хронологическое обозрение истории Новороссийскаго края. 1730-1823 (Aperçu chronologique de l'Histoire de la région Novorossiysk. 1730-1823), IIe partie, Odessa, Éditions Nitshche.

Smeu G., 1997, «Cantemir Dimitrie», Dicționar de Istoria Românilor, Bucureşti, Trei.

Stănescu E., 1971, «Byzance et les Pays roumains aux IX ${ }^{\mathrm{e}}-\mathrm{XV}^{\mathrm{e}}$ siècles », in: Actes du $X I V^{e}$ Congrès international des études byzantines, Bucarest, Editura Academiei Republicii Socialiste România.

Stratievskiy K., 1995, Changements dans la division administrative dans la population de la RASSM. 1924-1940, Revista de Istorie a Moldovei, numéro 2. 
Sturdza M.D., 1971, «La Russie et la désunion des principautés roumaines. 18641866 », Cahiers du monde russe et soviétique, année 1971, volume XII, numéro 3: 247-285, voir http://www.persee.fr/web/revues/home/prescript/article/ cmr_0008-0160_1971_num_12_3_1843

Svinine P.P., 1867, «Описание Бессарабской области. Составлео в 1816 » («Description de la région de Bessarabie. Composé en 1816»), in: Notes de la société d'histoire et des antiquités d'Odessa, volume VI, Odessa, ZOOID.

Țăranu M., 2010, La constitution de la RSSM a eu des conséquences tragiques, 2 août 2010, voir http://www.timpul.md/articol/-constituirea-rssm-a-avut-consecintetragice-mariana-taranu-13925.html

Thedrel A., 2009, "Il est une petite république autonome que le démon du séparatisme démange...», le Figaro, 29/07/2009, voir http://www.lefigaro.fr/ international/2009/07/29/01003-20090729ARTFIG00299-il-est-une-petiterepublique-autonome-que-le-demon-du-separatisme-demange-.php

Tofan A., 2008, «Personalitatea lui Dimitrie Cantemir în discursul identitar basarabean din perioada interbelică » («La personnalité de Dimitrie Cantemir dans le discours identitaire bessarabien de la période interbellique»), Limba Română, $\mathrm{n}^{\circ} 1-2$, année XVIII, voir http://limbaromana.md/index.php?go=articole\&n=573

Tudor T., 2004, Istoria dramatică a teritoriilor româneşti ocupate. Tratatul cu Ucraina (Histoire dramatique des territoires roumains occupés. Traité avec l'Ukraine), Bucureşti, Editura Albatros.

Ureche G., 1998, Letopisețul Tării Moldovei (Chronique du pays de Moldavie), Chișinău, Litera, voir http://fr.scribd.com/doc/15686875/Grigore-UrecheLetopisetul-Tarii-Moldovei

Văratec V., 2000, Preliminări ale raptului Basarabiei si Nordul Bucovinei. Documente. 1938-1940 (Préliminaires du rapt de la Bessarabie et du Nord de la Boucovine. Documents. 1938-1940), Bucureşti: Libra, 2000.

Vighel F., 1865, Восспоминания (Mémoires), volume VI, Moscou, Université.

Vilaldach F., 1999, «Entre le marteau russe et l'enclume roumaine», Regard sur l'Est, 01/04/1999, voir http://www.regard-est.com/home/breve_contenu.php?id=592

Xenopol A.D., 1885, Une énigme historique, Les Roumains au Moyen-Âge, Paris, Ernest Leroux Editeur, voir http://www.archive.org/stream/unenigmehistor00xn/ unenigmehistor00xn_djvu.txt

Xenopol A.D., 1896, Histoire des Roumains dès la Dacie Trajane: depuis les origines jusqu'à l'union des principautés en 1859, Paris, Ernest Leroux Editeur, voir http://archive.org/ stream/histoiredesroma00rambgoog/histoiredesroma00rambgoog_djvu.txt

Xenopol A.D., 1908, Les Roumains. Histoire. État matériel et intellectuel. Huit leçons faites au Collège de France en 1908. Paris, Librairie Ch. Delagrave. http:// upload.wikimedia.org/wikipedia/commons/e/e3/Alexandru_D._Xenopol_-_ Les_Roumains._Histoire_\%C3\%A9tat_materiel_et_intellectuel_-_Huit_ le\%C3\%A7ons_faites_au_College_de_France_en_1908.pdf 
Wheatley J., 2007, «Le nationalisme “civique" et “ethnique" revisité. La conceptualisation de l'État, de la nation et du citoyen dans l'ex-Union Soviétique », in Annuaire Français de Relations Internationales, volume VIII: 159-179, voir http://www.diplomatie.gouv.fr/fr/IMG/pdf/11_Wheatley.pdf

Weinreich U., 1975, "Contact linguistique et contact socioculturel», in: IonescuRuxandoiu L., Chitoran D., Sociolingvistica, București, Didactica și Pedagogica, p. $40-46$.

Werth N., 1993, «Moldavie 1992», L'État du monde 1992, Paris, La Découverte, voir http://www.afebalk.org/edm/articles.php3?id_article=70

Werth N., 1995, «Moldavie 1994», L'État du monde 1994, Paris, La Découverte, voir http://www.afebalk.org/edm/articles.php3?id_article $=72$

Werth N., 2009, «Les crimes de masse sous Staline. 1930-1953», Encyclopédie en ligne des violences de masse, 28 décembre 2009: 2-19, voir http://www.massviolence. org/IMG/article_PDF/Les-crimes-de-masse-sous-Staline-1930-1953.pdf Yacoub J., 1995, Les minorités. Quelle protection?, Paris, Desclée de Brouwer.

Zasciuk A.I., 1862, Бессарабская область. Материаль дня геограбии и статистики России (Région de Bessarabie. Matériaux géographique et la statistique de la Russie), volume I, Saint-Pétersbourg, DPEM

\section{Autes documents}

Constitution de la RM, du 29 juillet 1994, MO, nº1, du 12 août 1994.

Décision du Parlement de la RM relative à la Déclaration de la souveraineté de la RSSM, n¹48-XII, du 23 juin 1990, Veștile RSSM, n8/192, du 30 août 1990.

L. relative au retour de la langue moldave à la graphie latine, $n^{\circ} 3462-X I$ du 31 août 1989, Veştile RSSM, nº/214, 1989.

L. sur le statut de la langue officielle de la RSSM, n³464-XI du 31 août 1989, Veştile RSSM, $\mathrm{n}^{\circ} 9 / 216,1989$.

L. sur le fonctionnement des langues sur le territoire de la RSSM, n³465-XI du 01 sept. 1989, Veştile RSSM, nº/217, 1989.

Loi n²50-XII relative à l'élection du Président de la RSSM, du 3 sept. 1990, Vestile.

L. relative au changement du nom de la l'État de la RSSM en République de Moldova, n589-XII, du 23 mai 1991, MO, n006, du 23 mai 1991.

L. du Soviet suprême de la RSSM, n589-XII du 23 mai 1991, MP.

L. sur la Déclaration d'Indépendance de la RM, n691-XII, du 27 août 1991, Moniteur du Parlement de la RM, nos 11-12/103, du 30 déc. 1991.

L. sur le statut juridique spécial de la Gagaouzie (Gagauz-Yeri), n³44-XIII, du 23 déc.1994, MO, n³-4/51, du 14 janv. 1995.

L. relative à l'organisation administrative et territoriale de la RM, nº191-XIV, du 12 nov. 1998, $M O, \mathrm{n}^{\circ} 116$, du 30 déc. 1998. 
Règlement Loi Fondamentale de la Gagaouzie, Conseil de l'Europe, CDL(1998)024frev-restr, 28 mai 1998, voir http://www.venice.coe.int/webforms/documents/ CDL(1998)024rev-f.aspx

Conseil de l'Europe, Convention-cadre pour la protection des minorités nationales, Strasbourg, 1 février 1995, voir http://conventions.coe.int/treaty/fr/Treaties/Html/157. htm

Pacte germano-soviétique de non-agression Ribbentrop-Molotov. 23 août 1939, voir http://fr.wikisource.org/wiki/Pacte_Molotov-Ribbentrop

Comité Exécutif de la Gagaouzie. Unité territoriale autonome dans le cadre de la République de Moldova, Despre Găgăuzia (Sur la Gagaouzie), 2013, voir http:// www.gagauzia.md/pageview.php?l=ro\&idc $=400$

Gouvernement de la RM. Rapport soumis par la République de Moldavie en vertu de l'art. 25, al. 1, de la Convention-cadre pour la protection des minorités nationales, Chișinău, 29 juin 2000.

Organisation internationale de la Francophonie. Observatoire de la Délégation à la Paix, à la Démocratie et aux Droits de l'Homme, Roumanie. Rapport de la mission d'observation des élections résidentielles, législatives et sénatoriales du 27 septembre 1992, voir http://democratie.francophonie.org/rubrique.php3?id_ rubrique $=633$

Conseil de l'Europe. Assemblée parlementaire, 2002, Fonctionnement des institutions démocratiques en Moldavie, Résolution 1280 (2002), 24 avril 2002, 12e séance, voir http://assembly.coe.int/Documents/AdoptedText/ta02/FRES1280.HTM

Conseil de l'Europe, Rapport sur la demande d'adhésion de la Moldova au Conseil de l'Europe, Document. 7278, 18 avril 1995, voir http://www.assembly.coe.int/ASP/ Doc/XrefViewHTML.asp?FileID=6851\&Language $=F R$

Conseil del'Europe, Règlement, la loi Fondamentale de la Gagaouzie, CDL(1998)024frev-restr, Commission de Venise, Strasbourg, 28 mai 1998, voir

http://www.ecmimoldova.org/fileadmin/ecmimoldova.org/docs/Gagauz.Official/ Legal\%20Code\%20of\%20Gugazia-28.05.1998\%20_French_.pdf

Sénat, Commission des Affaires étrangères, de la défense et des forces armées, Rapport d'information: «La Moldavie: bâtir les fondements de l'identité nationale» fait par les Sénateurs Dulait A., Boyer A., Rouvière A., Les rapports du Sénat, $\mathrm{n}^{\circ} 102$, 1999, voir http://www.senat.fr/rap/r99-102/r99-1020.html 